NBER WORKING PAPER SERIES

\title{
IVORY TOWER VERSUS CORPORATE LAB: \\ AN EMPIRICAL STUDY OF BASIC \\ RESEARCH AND APPROPRIABILITY
}

\author{
Manuel Trajtenberg \\ Rebecca Henderson
}

Adam Jaffe

Working Paper No. 4146

\section{NATIONAL BUREAU OF ECONOMIC RESEARCH 1050 Massachusetts Avenue Cambridge, MA 02138 \\ August 1992}

We gratefully acknowledge support from the National Science Foundation through grant SES91-10516, and from the Ameritech Foundation via the Ameritech Fellows program of the Center for Regional Economic Issues at Case-Western Reserve University. This paper is part of NBER's research program in Productivity. Any opinions expressed are those of the authors and not those of the National Bureau of Economic Research. 
NBER Working Paper \#4146

August 1992

\title{
IVORY TOWER VERSUS CORPORATE LAB: AN EMPIRICAL STUDY OF BASIC RESEARCH AND APPROPRIABILITY
}

\begin{abstract}
We explore the use of patent citations to measure the "basicness" and appropriability of inventions. We propose that the basicness of research underlying an invention can be characterized by the nature of the previous patents cited by an invention; that the basicness of research outcomes relates to the subsequent patents that cite an invention; and that the fraction of citing patents that are assigned to the same organization as the original invention is a measure of appropriability. We test the validity of these presumptions by comparing the value of our measures for university and corporate patents, and find that many of the measures do conform to our a priori belief that university research and research outcomes are more basic and harder to appropriate than those of corporations. We also find some evidence that basicness of outcomes is correlated with basicness of research, and that appropriability is lower for basic outcomes.
\end{abstract}

Manuel Trajtenberg

Tel Aviv University

Ramat Aviv

Tel Aviv 69978

ISRAEL and NBER

Adam B. Jaffe

Department of Economics

Harvard University

Cambridge MA 02138

and NBER
Rebecca Henderson

Sloan School of Management

MIT

Cambridge, MA 02139

and NBER 
"It is the taste for the lifestyle of academic science, the compatibility of research with teaching, and the persistence of public authorities in subsidizing science at a level to which none of the constituents rould willingly subscribe, that prevent the collapse of the economic structure erected upon a high level of scientific activity. If the support were to be removed, the effects in our view would be quite disastrous."(Dasgupta and David, 1987)

\section{Introduction}

Economists have long understood that the peculiarities of information as a commodity, and the resulting imperfections in the market for new knowledge, severely limit the appropriability of the returns to innovation (Arrow, 1962, Levin et al, 1987, Cohen and Levin, 1989). Although appropriability problems plague all forms of research investment, they are thought to be more severe as we move from applied to more basic research. This view has supported a partial social division of labor whereby public institutions such as universities perform most of the basic research, and private firms do the R\&D necessary to commercialize the fruits of advances in scientific knowledge.

The unambiguous association of "basicness" with "low appropriability" is, however, becoming increasingly untenable. First, there is the simple observation that some profit-making firms do perform basic research, and the empirical evidence indicates that it is very profitable (Griliches, 1986). Either the motives of firms for performing basic research are more complex than previously thought, or the nature of such research cannot be defined just in terms of appropriability (Cohen and Levinthal, 1989, Mowery and Rosenberg, 1989). Second, there is much current interest in the role of universities in explaining the technology-based growth of particular regions, such as Route 128 around Boston or Silicon Valley in California (Dorfman, 1988; Jaffe, 1989). This geographic localization of the benefits of university research suggests that basic research results do not spill out as easily, as widely, or as quickly as the traditional view would suggest.?

In our view, better understanding of these phenomena requires

1 Our companion paper (Jaffe et al, 1992) looks explicitly at the extent of geographic localization of knowledge spillovers. 
clarification of concepts that are often used interchangeably. The notion of basicness of research relates to the kinds of questions that researchers ask, and how their work relates to the pre-existing body of knowledge. The notion of the basicness of research outcomes relates to the role of innovations as stepping stones to subsequent technological developments. Appropriability, in turn, relates to the attributes of innovations that make it easier for their developer to convert social returns into private rents. Stated this way, the conventional view of basic research rests on implicit assumptions that basic innovations are produced by basic research, and that basic innovations are relatively difficult to appropriate. These conjectures have important policy implications, and yet they have never been subjected to rigorous empirical scrutiny, probably because of the lack of suitable empirical counterparts to the concepts involved.

In this paper we intend to turn these assumptions into testable hypotheses. This requires us to identify the attributes of research and of research outcomes associated with basicness and with appropriability, to find measurable proxies for these attributes, and to "validate" these measures statistically. We can then investigate how the basicness of innovations relates to the basicness of the underlying research, and how both influence appropriability. We propose to do this using detailed patent data and patent citations in particular, because these citations provide good evidence of the links both between an innovation and the body of knowledge that preceded it, and between an innovation and the technological developments that it led to. We use matched samples of university and corporate patents to exploit our prior that university research is more basic than corporate research, and rely on the contrast between them to "validate" the measures.

The emphasis in the paper is thus on developing new ways to measure some key but elusive concepts in the economics of technical change that have so far defied systematic quantification. This paper can also be seen as a pilot study, in that its empirical findings should help decide whether or not it would be justified to pursue this line of research in "full scale". He begin in section 2 with a background discussion of the different notions of basic 
research, and the use of patent data in such context. In section 3 we introduce the proposed measures of basicness and appropriability, and elaborate on their construction and interpretation. Section 4 dwells on the design of the sample, and the related validation procedure for these measures. The empirical results are presented and analyzed in section 5 . We find that our measures capture indeed important aspects of basicness and of appropriability; that there seem to exist "technological trajectories" showing persistence and coherence; that some of the features of innovations are related to some of the attributes of the underlying research, and similarly that appropriability is associated just with some aspects of basicness - the simplistic notion of a one-to-one equivalence between these concepts is therefore not varranted. We summarize the findings in section 6 , and suggest various ways to further pursue this line of research.

\section{Background}

\subsection{Definitions of Basic Pesearch}

The distinction between basic and applied research is widely used and has existed for a long time, and yet the underlying notions remain ill-defined. Thus, for example, while economists tend to think of basic research in terms of the difficulty with which it can be appropriated, scientists view it mostly in terms of its relationship to prior research, or in terms of its scientific and technological impact. The tacit assumption underlying most of this literature is that these views are necessarily equivalent, but on close examination the presumed equivalencies are far from certain.

The scientific and technological literature characterizes as "basic" research that focuses on scientific rather than on technological questions; that seeks to elucidate general laws rather than solving particular technical problems; that draws upon new scientific principles and offers original solutions to old puzzles (e.g. Kuhn, 1962; Rosenberg,1982). Thus for example, the research activities of the team headed by William Shockley at the Bell Labs that led to the discovery of the transistor can be seen as basic in this sense (Nelson, 1962). 
This same literature, however, often defines what is basic according to the nature of the outcomes of the research enterprise: research is regarded as basic if it is uniquely innovative and represents breakthroughs relative to existing knowledge; if its results have a major impact upon a given field (e.g. Watson and Crick's discovery of DNA), or a diffused but significant impact across a broad range of fields (e.g. the laws of thermodynamics, the mathematics of chaos); if they turn out to be fundamental to much later work, and are often referred to by scientists and practitioners in the same or other fields.

The closest to an "official" definition of basic research is that of the National Science Foundation, which bases it on the motivations and goals of the researcher: research is defined as basic if it has as its objective "a fuller knowledge or understanding of the subject under study, rather than a practical application thereof"; conversely, applied research is seen as directed toward gaining "knowledge or understanding necessary for determining the means by which a recognized and specific need may be met" (NSF, 1985, p. 221). ${ }^{2}$

Economists, in turn, tend to characterize basic research according to the features of the outcomes of research that are of economic relevance, rather than according to the features of research activities per se. Thus, basic research is often defined implicitly as research that leads to basic innovations, which are characterized in turn as generating benefits that are exceedingly difficult to appropriate (in the sense of a low expected ratio of private to social returns). ${ }^{3}$ Nelson (1959), for example, argued that firms

${ }^{2}$ These definitions are important in that they are used in the science and technology surveys conducted by the NSF, which constitute one of the main sources of statistical information on the magnitude and composition of research activities and R\&D expenditures in the USA. 3To illustrate, consider the following quotes: "Its 'output' [of R\&D] is
the flow of new information, both of general character (the result of 'fundamental' or 'basic' research) and relating to specific applications ("applied' research)." Freeman, 1982, p. 10; "Thus basic research, the output of which is only used as an informational input into other inventive activities, is especially unlikely to be rewarded." Arrow (1962), p. 618; 
would be able to reap only a small fraction of the benefits of basic research, since they have difficulty commercializing results in fields other than or far from their existing product line. Thus the nature of the results of basic research makes it hard to establish property rights that would prevent their exploitation by others. Similarly, basic research is thought to be riskier and to have longer lead times than more applied research, which would also limit its appropriability.

In order to prepare the ground for the actual measurement of basicness and appropriability, and following Kuznets (1962), we vould like to draw a clear distinction between research on the one hand, and innovations (or research outcomes) on the other, mimicking in this context the classic input-output divide. From this follows an equally sharp distinction between basicness of research as a characteristic of the activities leading to innovations, and basicness of innovations, which is a feature of the outcomes of such activities. 1

Moreover, these distinctions imply that the nature and strength of the links between basicness of research and basicness of innovations are an open empirical question, and not necessarily a one-to-one correspondence. This is so because of the high degree of uncertainty that characterizes research, and the serendipitous character of so many important innovations. 5 Thus defining

"The payof [to basic research] is uncertain and distant, and the knowledge
quickly moves into the public domain"; "The output [of basic research] is a
peculiar kind of good that may be used, not to produce a final good, but to
play some further role in the invention of a new final good". Mowery and
Rosenberg (1989), pp. 10 and 11 .
4It should be clear that the "basic versus applied research" dichotomy is
just a coarse two-way partition of a composite attribute of research that is
essentially continuous, and which we shall refer to as "basicness" (we use
this characterization also for innovations).

sThere are plenty of historical examples of breakthroughs made by researchers while pursuing research goals that would surely qualify as applied research; see for example the cases of Pasteur, Carnot and Jansky as described in Howery and Rosenberg (1989). Although more difficult to document, it is equally clear that a great deal of what is regarded as "basic research" does not lead to important innovations: uncertainty works both ways. 
the nature of research according to the nature of the outcomes begs the question of what either of them truly is, at least for the purpose of quantification. Similarly, the relationship between the degree of appropriability of the benefits from innovations on the one hand, and the characteristics of the underlying research and of the innovation itself on the other, is a compelling issue for investigation, not a foregone conclusion.

Finally, a rord of caution: definitional matters can easily turn into mine fields, where semantics overwhelms substance. We are not interested in taxonomies or definitions per se; rather, we vant to shed light on the measurable characteristics of the process that leads to innovations, and their relationship to the economically relevant attributes of the innovations themselves, as these are revealed ex post. We intend also to clarify the links between the concepts defined here and commonly held notions of basicness and appropriability, hoping that this will facilitate the analysis of R\&D and innovation as empirical phenomena.

\subsection{The Use of Patent Data}

The measures of basicness and appropriability that we put forward here rely exclusively on information contained in patents. Ve are thus tapping one of the richest source of data on innovations, and certainly the one with the widest coverage. We intend to exploit detailed information that appears on individual patents, and not just patent counts as has been common practice in much of the research in this area. ${ }^{8} 7$

${ }^{8 \mathrm{~A}}$ great deal of research in economics has used patents as indicators of various aspects of the innovation process, with varying degrees of success (see e.g. Griliches, 1984 and 1990; Jaffe, 1986); related work has shown that patent citations contain information about the value of patents and the links among them (Carpenter et a1, 1981; Carpenter and Narin, 1983; Trajtenberg, $1990 \mathrm{a}$ and 1990b).

7Kuznets had foreseen long ago the potential of patents as a rich source of data far beyond mere patent counts: "...the mere number of patents, or even their classification... is only a fraction of the information in the files of patent offices... such information... is conceivably raw material for a more intensive study of the output of inventive activity... [it] would permit indentification of the patentors, and provide an initial step in the study of the characteristics of inventors that is indispensable for a better analysis 
A patent is a temporary monopoly awarded to inventors for the commercial use of a newly invented device. For a patent to be granted, the invention must be non-trivial, meaning that it would not appear obvious to a skilled practitioner of the relevant technology, and it must be useful, meaning that it has potential commercial value. If a patent is granted, an extensive public document is created. The front page of a patent contains detailed information about the innovation, the inventor, the assignee, the technological antecedents of the invention, etc. all of which can be accessed in computerized form (see figure 1 ).

An item of particular importance for our purposes is the citations to previous patents (see item 56 on figure 1, "references cited"): we believe that the notion of "basicness of research" is embodied in the relationship between the innovation and its technological antecedents, and likewise that the essence of "basicness of innovations" is embodied in the relationship of the research outcomes to subsequent technological developments. Patent citations, made and received, provide an effective means for identifying and tracing these relationships.

Patent citations serve an important legal function, namely, they delimit the scope of the property rights avarded by the patent. Thus, if patent 2 cites patent 1, that means that 1 represents a piece of previously existing knowledge upon which patent 2 builds, and over which 2 cannot have a claim. The applicant has a legal duty to disclose any knowledge of the prior art, but the decision of which patents to cite ultimately rests with the patent examiner, who is supposed to be an expert in the area and hence to be able to identify relevant prior art that the applicant misses or conceals. 8 The

of the supply side of inventive activity". Kuznets (1962), p. 40.

${ }^{8}$ Thus there is reason to believe that the use of patent citations to trace technological linkages is more "robust" and less "noisy" (in the sense of the role played by extraneous motives in the decision of what to cite) than the reliance upon other bibliographic data such as citations in the scientific literature (Van Raan, 1988; Veingart et ol, 1988). Moreover, these other bibliometric techniques are of limited value in tracing the economic impact of scientific results, since they are entirely self contained. 
framework for the search is the patent classification system, which currently consists of over 100,000 patent subclasses, aggregated into about 4003 -digit patent classes. The combination of the citation information with detailed information about each applicant provides a unique mechanism for placing research and research results in their broader technological and economic context.

Two important limitations of the reliance on patents for our purposes should be mentioned: first, the range of patertable innovations constitutes just a sub-set of all research outcomes, and second, patenting is a strategic decision and hence not all patentable innovations are actually patented. As to the first, consider Figure 2.a where we depict "basicness" as a measurable feature of research outcomes, that ranges from the most applied on the left to the most basic on the right. Clearly, neither end of the continuum is patentable: "Yaxwell's equations" could not be patented since they do not constitute a device (ideas cannot be patented); on the other hand, a marginally better mousetrap is not patentable either, because the innovation has to be "non-trivial".

There is some internal range of unknown width that is patentable; within it we believe that patents and patent citations can be used successfully to measure the relative basicness of innovations. Obviously, research that produces outcomes outside this range will not be picked up by our measures, at least not right away. However, if unpatentable basic scientific discoveries eventually do bring about technological advances of potential commercial significance, at some point patents will be observed and hence measures of this sort will probably pick them up. Thus, the patentability requirements restrict the scope of our measures such that purely scientific advances, devoid of immedicte applicability are excluded, as well as run-of-the-mill technological improvements that are too trite to pass for discrete, codifiable innovations.

The second limitation has to do with the fact that, due to strategic or other considerations (such as different motivations or revard systems), 
inventors may decide not to apply for patents even though their innovations would pass the patentability requirements. In other words, the "propensity to patent" may vary across inventors, perhaps in a systematic way. For example, until recently universities could not obtain patents based on federally funded research (which is about $90 \%$ of university research), and hence it is likely that many of their innovations were not patented. Firms, on the other hand, may elect not to patent and rely instead on secrecy to protect their property rights, and this practice may be more common in certain industries than in others (see Levin et al, 1987). Aside from restricting the potential coverage of our measures (again to an unknown extent), the question is whether these limitations may affect the statistical properties of our measures; this issue is discussed in section 4.2 .

\section{Measures of Basicness and Appropriability}

The measures that we put forward here are grounded in a view of technical advance as a process that unfolds over time, displaying coherence and cumulativeness. Within such a framework each individual innovation is but a node, a juncture alongside the innovational strean to which it belongs, that builds upon what came before, and creates opportunities for future invention. Thus each innovation has a past and a future: there is a body of knowledge that precedes and feeds into it, and there are down-the-line technological advances that stem from and build upon it. Clearly, basicness as discussed above can be ascertained only as we look back and forth over time: a snapshot of an innovation taken in isolation cannot reveal its impact or its standing vis-a-vis past and future.

Ve propose, accordingly, two sets of measures: ${ }^{9}$ the first looks at

-Since this is virtually the first time that measures of this sort have been constructed (except for citation counts), we had to do a great deal of search and experimentation until we "converged" to the set of measures reported here. The measures discarded were statistically undistinguishable from the measures kept, and/or devoid of a clear interpretation. The good news is that the final set appears to be "robust", in the sense that we kept getting virtually the same results with the many variants that we tried. Still, this can only be regarded as a tentative set, and only further research can confirm its usefulness and significance. 
basicness as an attribute of the research that lead to the patent being evaluated (the "originating" patent), 10 the second refers to the posterior impact of the innovation. Thus, we base the former, which we refer to as "backward-looking" measures ("B/measures" in short), upon the characteristics of the patent's predecessors, both in themselves and vis a vis the attributes of the originating patent. Similarly, we construct the "forward-looking" ("F/") measures on the basis of data on the patents that subsequently cite the originating patent.

Aside from basicness proper, we compute measures of "distance" in time and technology space both between the innovation and its predecessors, and between the innovation and its offsprings. The presumption is that remoteness in time and technology may be related to aspects of basicness or, more likely, to the conditions of appropriability. Finally, we propose a measure of actual (or ex post) appropriability, both $F$ and $B$. For the definition and computation of the measures we use the following notation (refer to figures 4 and 5 ):11

NCITING: number of patents citing the originating patent ("o-patent").

NCITED: number of patents cited by the 0 -patent.

NPCITES: number of non-patent sources cited by the o-patent.

NCLASS: 3-digit original patent class.

CATCODE: 2-digit "technological class", which aggregates up NCLASS

FIELD: 1-digit classification by main technological fields.

LAG: difference in years between the application date of a citing or cited patent, and the application date of the 0 -patent.

Index $i$ corresponds to the o-patent, $i+1$ to citing patents, and $i-1$ to cited patents. All measures but one ("SCIENCE") will be defined and computed

${ }^{10}$ For expositional convenience we shall use from now on the terms "patents" and "innovations" interchangeably, even though we are very mindful of the fact that, as commonly understood, the overlap between them is by no means full.

$11 \mathrm{CATCODE}$ is taken from Jaffe (1986). The technological areas in FIELD are, 1: Drugs and Medical; 2: Chemical (except Drugs); 3: Electronics, 
in equivalent ways backwards and forward; however, their precise meaning and interpretation varies in some cases across the forward/backward (F/B) divide.

\subsection{Veastres of Basicness}

The first, and probably the key aspect of F/basicness is what we call the overall "importance" of a patent, denoted IMPORTF (the $\mathbf{F}$ for forward), which corresponds to the most intuitively appealing notion of what basic innovations are all about. In the words of Kuznets (1962),

"Some inventions, representing as they do a breakthrough in a major field, have a wide technical potential in the sense that they provide a base for numerous subsequent technical changes [our emphasis]...the first steam engine, which initiated a whole series of major technical changes and applications... is vastly different from the invention of the safety match or the pocket lighter. This wide range is for our purposes the major characteristic relevant to the problem of measurement". (p. 26).

Thinking of citations to a patent as coming from follow-up advances that at least in part build upon or stem from the originating patent, we would like IMPORTF to reflect both the number of subsequent citations, and their importance. Thus we define (see figure 4),12,13

$$
\text { IMPORTF }_{i}=\text { NCITING }_{i}+\lambda \sum_{j=1}^{\text {ncitingi }} \text { NCITING }_{i+1, j}
$$

where $0<\lambda<1$ is an arbitrary "discount factor" that is meant to

Optics and Nuclear; 4: Mechanical Arts; 5: Other.

$12 \mathrm{As}$ mentioned before, citations counts have been used in previous research as an indicator of the importance or value of patents; thus for example, Trajtenberg (1990) found that patents weighted by citations are highly correlated over time with the social gains from innovation in a particular industry. The only difference is that here we augment IMPORTF with "second- eneration" citations, thus basing it on more extensive information on the subsequent impact of the patent.

${ }^{13}$ Notice that the unavoidable truncation of the data at the point in time when the data are collected $(T)$ means that NCITING $_{i+1, j}$ (that is, the number of citations to citing patents) is necessarily a partial measure of importance of the citing patents; thus, IMPORTF should be taken to mean the "importance" of patent $i$ os revealed - or realized - up to $T$. 
downweight the "second-generation" descendants of a patent relative to the first-generation citing patents. In all calculations reported here we have set $\lambda=0.5$, but none of the results appear to depend upon it (we experimented with values of $\lambda$ in the $0.25-0.75$ range).

The second notion of $\mathrm{F} /$ basicness is that of "generality" (GENERAL), that is, the extent to which the follow-up technical advances are spread across different technological fields, rather than being concentrated in just a few of them.14 Ve compute GENERAL on the basis of the Herfindahl index of concentration, whereby the number of citations in each 3 -digit patent class (NCLASS) plays the same role as the sales of each firm in the traditional industrial organization context, that is,

$$
\text { GENERAL }_{i}=1-\sum_{k=1}^{N_{i}}\left(\text { NCITING }_{i k} / \text { NCITING }_{i}\right)^{2}
$$

where $k$ is the index of patent classes, and $\mathrm{N}_{i}$ the number of different classes to which the citing patents belong. Notice that $0 \leq$ GENERAL $\leq 1$, and that higher values represent less concentration and hence more "generality".

Turning now to the B/measures (that is, to basicness of research), we define the equivalent to IMPORTF as,

$$
\text { IMPORTB }_{i}=\text { NCITED }_{i}+\lambda \sum_{j=1}^{\text {ncitedi }} \text { NCITING }_{i-1, j}
$$

Thus, IMPORTB will be large if the o-patent cites many previous patents, and these cited patents are "important" in the usual sense that they in turn vere highly cited (as with IMPORTF we use $\lambda=0.5$ ). In other words, IMP0RTB

14 Thus for example, if a patent in solid-state physics is cited by later patents in chemistry, in superconductivity and in medical instrumentation, we vould regard it as more general, and hence more basic, than a similar patent that received the same number of citations but all or most of them belong to the same field. 
reflects the extent to which a given o-patent stands on a wide base of previous innovations which are in themselves important. However, and unlike IMPORTF, it is not entirely clear how IMPORTB relates to basicness: the presumption is that IMPORTB is an aspect of originality or creativity, in that more original patents would have fewer and/or less important predecessors and therefore lower values of IMPORTB. On the other hand it could be that "importance breeds importance," and hence patents that prove ex post to be successful would tend to display higher values of IMPORTB as well. The equivalent $B$ /measure for GENERAL, which we label ORIGINAL, is defined as,

$$
\operatorname{ORIGINAL}_{i}=1-\sum_{k=1}^{\mathrm{N}_{i}}\left(\operatorname{NCITED}_{i k} / \operatorname{NCITED}_{i}\right)^{2}
$$

Thus the larger is ORIGINAL the broader are the technological roots of the underlying research. Since synthesis of divergent ideas is arguably an element of originality, we conjecture that ORIGINAL captures indeed an aspect of B/basicness.15 Finally, we define a measure of scientific base which lacks a F/counterpart,

$$
\text { SCIENCE }_{i}=\text { NPCITES }_{i} /\left(\text { NPCITES }_{i}+\text { NCITED }_{i}\right) .
$$

that is, SCIENCE measures the predominance of scientific sources as proxied by NPCITES, 18 over technological ones (embedded in NCITED). The conjecture is that more basic research would tend to draw relatively more from science than

13 Veizman (1991) develops a "theory of diversity" which in priciple could be applied to the measurement of diversity of any set of interrelated objects (his particular motivation is the measurement of the value of diversity of things such as endangered species or architectural styles). However, his approach rests on a postulated binary distance metric, which is hard to visualize in our context.

16 These "non-patent references", which appear on the front page of patents under the heading "Other Publications" (see Figure 1), may include articles in scientific journals, books, abstracts, proceedings, etc. They constitute knowledge or ideas to which the patent is related, but do not carry the legal weight of patent citations. 
from technology, and hence would be associated with higher values of SCIENCE.

\subsection{Veasures of Distance}

The $F /$ looking time distance measure is defined simply as the average forward LAG, that is,

$$
\text { TIMEF }_{i}=\left(\sum_{j=1}^{\operatorname{nci}{ }^{\text {ing }}} \operatorname{LAG}_{j}\right) / \operatorname{NCITING}_{i}
$$

The $F /$ distance in technology space is computed as follows: if the citing patent is in the same 3 -digit class (NCLASS) as the 0 -patent, then the "distance" between them, TECH, is set to zero; if they are in the same 2-digit class (CATCODE) but not in the same 3 -digit class, then TECH $=0.33$; if they are in the same 1-digit class (FIELD) and not in the same 2- or 3-digit class, then $\mathrm{TECH}=0.66$; if they are even in different 1 -digit classes then $\mathrm{TECH}=1$. The average distance for o-patent $i$ is then,

$$
\operatorname{TECHF}_{i}=\left(\sum_{j=1} \operatorname{TECH}_{j}\right) / \operatorname{NCITING~}_{i}
$$

The equivalent B/distance measures, TIHEB and TECHB, are defined in an exactly analogous way, just by substituting NCITED for NCITING in these formula. Their interpretation is also straightforward: larger values of TIHEB would indicate that the o-patent draws from older sources, large values of TECHB that the innovation has roots in remote technological fields.

Whether or not these distance measures capture aspects of basicness is an open question. The (somewhat weak) presumption regarding TIMEF is that more basic innovations will take longer in generating offspring, since the technical difficulties of the required R\&D efforts would be commensurable to the degree of "basicness". As to TECHF, if basicness implies a higher probability of serendipitous discoveries, and if these tend to occur in remote technological areas, then it is plausible that the incidence of far-removed follow-ups would be higher the more basic a patent is. Hovever, it is not at all clear whether these "ifs" hold up in reality, and even if they do, it is 
not clear whether that would result also in a larger average technological distance. On the other hand, and as argued in section 5.4, it seems a priori more likely that the distance measures would be related to appropriability (the same applies to the B/measures, TIMEB and TECHB).

\subsection{Bx post appropriability}

The F/measure of actual appropriability that we propose, PSELFF, is defined simply as the percentage of citing patents issued to the same assignee as that of the 0 -patent. The rationale for this measure stems from the premise that citations reflect follow-up developments of the original innovation, and that these developments are the conduit that leads to the realization of benefits (by refining and improving the original innovation, and hence shifting downwards as it were its supply curve). Thus, the higher the proportion of these later developments that take place "in-house" the larger would be the fraction of the benefits captured by the original inventor. The equivalent B/measure, PSELFB, captures virtually the same notion, that is, it measures the extent by which the originating innovation represents appropriation of benefits to its predecessors. The presumption underlying both is that more basic innovations are more difficult to appropriate, and hence vill result in lower values of PSELF.

Schematically, the measures proposed are as follows:

\begin{tabular}{lcc} 
& Forward & Backwards \\
\cline { 2 - 3 } Basicness & IMPORTF & $\begin{array}{l}\text { IMPORTB } \\
\text { ORIGINAL } \\
\text { GENERAL }\end{array}$ \\
SCIENCE \\
Distance & TECHF & TECHB \\
TIMEF & TIMEB \\
Appropriability & PSELFF & PSELFB \\
\hline
\end{tabular}




\section{Research Design}

\subsection{Sample Design and Data Gathering}

Since this is essentially a pilot study (in that the emphasis is on constructing the measures and exploring their "validity" and feasibility for further research), we rely on a relatively small sample of patents, and hence we had to exercise a great deal of care in designing the sampling scheme. The main considerations vere: (i) we vanted to maximize the chances of seeing patents that span the patentable range illustrated in figure 2 ; (ii) since ve restricted ourselves to patent data, we wanted to be able to "validate" the proposed measures relying only on priors about the institutional distribution of basic research, that could be translated into the sampling scheme; (iii) we wanted to cover sufficiently long sequences of innovations so as to be able to compute measures that rely on backward and forward linkages; (iv) we needed to be able to control for technological areas, since citation practices may vary systematically across them.

Requirements (i) and (ii) led us to start from patents assigned to universities, and contrast them to matched samples of patents assigned to corporations: the presumption is that universities do more basic research, and hence that their patents would help cover the upper segment of the patentable range. 17 Hore importantly, that same prior would enable us to "validate" the proposed measures (see section 4.2). The drawback is that university patents constitute a tiny fraction of the universe of patents issued in the Us in any given year (less than one percent), and cannot be regarded as representative of patents at large. Hovever, since we do not purport here to characterize the "true" distribution of basicness across the whole population of patents, the extent to which the sample is representative is not of much consequence.

In order to satisfy (iii) ve took all university patents applied for in 1975 (316 patents) and in 1980 (482 patents), which gave us substantial time

17 Total research spending at universities and federally funded research and development centers was $\$ 12.1$ billion in 1987 (NSF, 1989); private firms reported that same year outlays of $\$ 2.7$ billion in basic research. 
horizons backwards and forward.18:19 We identified and gathered data on each of the (earlier) patents cited by these "originating" patents, and on each of the (subsequent) patents citing them, thus forming a complete set which encompasses three successive generations of related inventions (see figure 3 ). We also obtained the number of citations made and received by each of the cited and citing patents, which gave us some information about the "grandparents" and the "grandchildren" as well. Rarely does empirical vork examine such long stretches of the innovational stream.

To give us a base of comparison and increase the chances of seeing a substantial variance in the measures of basicness, we identified two samples of corporate patents in parallel to the university patents. The first was drawn from the universe of patents granted to the top $200 \mathrm{R} \& \mathrm{D}$-performing U.S. firms in 1986, as reported in 10- $K$ reports and coded by the Compustat data service. Ve expect that at least some of these firms perform appreciable basic research. The other corporate sample was drawn from the universe of patents assigned to all other U.S. corporations, which are by definition "smaller" in terms of $R \& D$ expenditures; presumably they engage in proportionally less basic research.

In order to control for technological field, each of these samples was drawn to match the university patent cohorts by patent class, application year and grant date. That is, for each originating university patent, we selected a corporate patent from each universe that had the same application year and

18 In principle there should always be enough of a backwards horizon, but in practice the availability of data declines dramatically as we go back in time, to the point that for the 1975 cohort, for example, a great deal of the data of the cited patents are missing, and that created serious problems in computing the measures. There is reason to believe though that this limitation vill soon vanish, as more and more patent data become computerized and available as such.

19 Ve succeded in gathering forward patent data only up to 1989 , primarily because we had to rely on "third parties" to obtain the data, and that meant long delays. Again, availability is improving by leaps and bounds, and costs of retrieving patent data from computerized searches are declining, so that in future research one should be able to obtain much more recent data. 
(3-digit) patent class as the university patent, and was granted as close in time as possible. This design allows us to compare averages of measures of basicness across institutional groups, without worrying that the estimates might differ only because universities and corporations exhibit different distributions of patents across fields. We then collected data on the predecessors and successors of these corporate patents, exactly in parallel to the set of university patents. As figure 3 makes clear, this sampling scheme lead to "explosive" data requirements: starting from just 319 university patents applied for in 1975 we ended up collecting data on over 10,000 patents, and likewise starting from 482 patents in 1980 the number climbed to over 15,000 .

\subsection{Talidation and Selectivity}

As mentioned above the choice of university patents as the "core sample" was meant to allow us to validate statistically the measures of basicness without having to resort to additional (external) information, but rather with reference to commonly held priors. In this section we discuss the rationale for this validation procedure, and the closely related issue of sample selection bias.

University patents constitute a tiny fraction of all patents issued in the U.S. and, given the institutional idiosyncrasies of universities they can hardly be regarded as "representative" of the universe of all U.S. patents. Moreover, the vast majority of research outcomes from universities do not lead to patents, for three distinct reasons: (1) if university research is indeed more basic, the distribution of outcomes will be located over the right-hand segment of the continuum shown in figure 2, and therefore most of them vill not be patentable; (2) up to 1980 universities were precluded by law from charging royalties for patents stemming from federally funded research, which account for the bulk of university research; (3) the "propensity to patent" of university researchers is probably lover than that of their counterparts in corporations, since the incentives that they face (in terms of promotion, prestige, etc.) encourage primarily publication of research outcomes in the scientific literature. 
The question is whether the (small) sample of outcomes captured by university patents can be regarded as random or, if biased, whether the biases might affect the validity of our intended statistical analysis. In order to address this issue, we restate the research design in such a way as to clarify the roles played by priors, samples, and selectivity. Suppose that basicness is unidimensional, and that the goal is to find an indicator of basicness $b$ such that $\mathrm{E}\left(\mathrm{b}_{\mathrm{u}}\right)>\mathrm{E}\left(\mathrm{b}_{\mathrm{c}}\right) \Leftrightarrow \beta_{\mathrm{u}}>\beta_{\mathrm{c}}$, where the $\beta^{\prime} \mathrm{s}$ are the unknown parameters, $E(\cdot)$ denotes expected value, and $u$ and $c$ stand for different types of assignees (e.g. university versus corporations). In order to "validate" the use of $b$ as an indicator we rely on the widely held prior that the distribution of basicness of the whole population of research outcomes from universities, $F_{u}$, lies to the right of the corresponding distribution for corporations, $F_{c}$ (see figure 2.a); thus, assuming that $F_{u}$ and $F_{c}$ belong to the same family of distributions, the prior implies that $\beta_{\mathrm{u}}>\beta_{\mathrm{c}}$. "Validation" of a particular measure $\mathrm{b}$ simply means in this context that, given appropriate samples and statistical tests, one rejects the null $\mathrm{H}_{0}:\left(\beta_{\mathrm{u}}-\beta_{\mathrm{c}}\right)=0$ using as a statistic $\left(\mathrm{b}_{\mathrm{u}}-\mathrm{b}_{\mathrm{c}}\right)$.

Notice that when focusing on validation the actual magnitudes of the $\beta_{\mathrm{i}}$ 's, or the proper way to estimate them is not an issue: all that counts is that there is a strong presumption that university research yields more basic outcomes than corporate research. It is thus immaterial for our purposes whether or not $\mathbf{E}\left(b_{i}\right)=\beta_{i}$. Rather, the issue is whether the sampling scheme affects the power of the test as described above. For it should be clear that, most of all, we need to guard against a type II error, which in the present context would mean accepting the null by virtue of a selectivity bias in the neasures.

How can that happen? Consider figure 2.b: if for example universities were patenting research outcomes coming just from the shaded area of $\mathbf{F}_{u}$ whereas corporate patents vere drawn randomly from the whole distribution $F_{c}$, such that $E\left(b_{u}\right) \gg \beta_{u}$ and $E\left(b_{c}\right) \cong \beta_{c}$, then it is clear that the proposed validation procedure would not be valid: had the sample of university outcomes 
been truly random, we may well have found that $E\left(b_{u}\right)<E\left(b_{c}\right)$, in which case $b$ could not be regarded as a good proxy for basicness. Thus, it is clear that the condition for the "validity" of the proposed test, in the sense of yielding a small probability of type II error, is

$$
\mathrm{E}\left(\mathrm{b}_{\mathrm{u}}\right)-\beta_{\mathrm{u}} \leq \mathrm{E}\left(\mathrm{b}_{\mathrm{c}}\right)-\beta_{\mathrm{c}}
$$

Can we presume it to be fulfilled? Quite likely so, considering that the reasons that account for the small number of research outcomes patented by universities imply also that university patents are most likely drawn from an area such as the shaded one in figure 2.c, and hence that $E\left(b_{u}\right) \ll \beta_{u}$. Horeover, if university patents stem mostly from privately funded research, it is quite likely that such research would be from the outset aimed at more "applied" outcomes than research funded by the government, which is supposed to advance precisely those areas of science that have no immediately apparent commercial benefits. On the other hand, it is not clear whether and how the incentives of corporations to patent may vary along the range of $\boldsymbol{F}_{c}$. It is quite likely that corporations also tend to patent less basic research outcomes than their own mean, but it is highly implausible that they will restrict themselves to a narrow segment far left as universities presumably have been doing, at least until 1980 .

To sum up: university patents constitute by no means a random sample of university research outcomes, and probably corporate patents are not drawn randomly from the distribution of corporate research either. However, there is a strong presumption that condition (1) holds, and hence that the selectivity biases inherent to the sample scheme are immaterial to the goal of validating the measures of basicness. Notice though that not much can be said if the results happen to be "weak" (i.e. if some of the differences between the $b_{u}$ 's and the $b_{c}$ 's turn out to be not very significant): that may well be due to the selectivity biases, which would translate into substantial probabilities of type I error. Better that than risking over optimistic inferences as to the effectiveness of the proposed indicators. 


\section{Statistical Analysis and Results}

\section{1 \& first look at the measures}

Tables 1 and 2 present descriptive statistics of the measures and Pearson correlations between them, and figures 5 and 6 depict the empirical distributions of some of them (see the appendix for additional details). Notice first the striking similarity in the shape of the distributions of IMPORTF and IMPORTB, and likewise for GENERAL and ORIGINAL; as it turns out, this is true for all equivalent $F / B$ measures, which is an interesting finding that deserves further scrutiny (see below, and the appendix).

As figure 5 shows, the distribution of IMPORTF is extremely skewed (for 1980 the mean is 12.6 and the median just 5.5 ). If we interpret IMPORTF as an indicator of the "value" of patents, the observed skewness would fit nicely with previous findings regarding the distribution of such values (e.g. Pakes 1986, Trajtenberg 1990): most patents turn out to be of very little value (i.e. to have few if any "descendants"), and only a handful "make it big". IMPORTB is similarly skewed, which would mean that most patents come from "humble origins", and few have important technological predecessors. Thus important innovations appear to be in very short supply as one looks either up or down the innovational stream.

The distributions of GENERAL and of ORIGINAL look much more "normal" (bell-shaped), except for the large mass at zero. Sixty percent of the patents with GENERAL $=0$ had just one citing patent, which means that GENERAL could only be zero; an additional 25\% of these patents had NCITING $=2$, which are very likely to render GENERAL $=0$. Still, the mass at zero is not an artifact: patents that "fathered" just one or two further technological developments can claim indeed little generality. 20

20 For ORIGINAL $=0$ the percentage of patents with $\mathrm{NCITED}=1$ or NCITED $=2$ was just $39 \%$ (25\% for 1975), thus it would seem that the finding of a large mass at zero is more telling for ORIGINAL than for GENERAL. The only qualification is that there are many missing backwards data, and thus many of the patents for which NCITED $=1$ or 2 might have received a value of zero for ORIGINAL (rather than missing) if the data had been available. 
Turning to the correlations between measures of the same type ( $F$ and $B$ ), notice in table 2 that the various measures do capture different aspects of the underlying phenomena: 21 none of the correlations exceeds 0.5 , most are much smaller. The variables that exhibit the largest pairwise correlations are GENERAL and TECHF and, in parallel, ORIGINAL and TECHB. This is not too surprising, since both measures refer to the positioning of patents in technology space.22 The other pair exhibiting a high correlation is IMPORTF and GENERAL, and likewise IMPORTB and ORIGINAL (see the appendix).

\section{2 "Palidating" the measures: comparison of means}

Table 3 presents simple comparisons of the sample means of the proposed measures between university and corporate patents. To recall, our prior is that research, and research outcomes from universities are "more basic" than those from corporations, and therefore if our measures do capture aspects of basicness university patents should rank higher than corporate patents along those dimensions.

IMPORTF strongly backs the prior: university patents received significantly more first- and second generation citations, and the difference seems to increase over time (see the results for 1975 vis a vis 1980). The figures for GENERAL indicate that the follow-up innovations from universities spread indeed more widely over different technological areas, but the 1975 results suggest that these differences tend to narrow down over time. In fact, we recomputed GENERAL for the 1975 cohort truncating the citation data in 1984 so as to replicate the time span of the 1980 sample, and the results are almost identical to those for 1980 . Thus at first the offsprings from corporate patents tend to be more technologically concentrated, but eventually these spillovers become more diffused, narrowing the gap in that respect

21 The results for the 1975 sample are very similar in every respect, hence we chose to show just those for 1980 .

22 GENERAL (ORIGINAL) refer to the spread over patent classes of the citing (cited) patents regardless of where the originating patent is located, whereas TECH ( $F$ and B) measures the average "distance" in that same space from the originating patent to the citing (cited) patent. 
between them and university patents. This fits nicely the common wisdom regarding the way spillovers work, and goes in tandem with the finding in our companion paper (Jaffe et al 1992) of diminishing geographic localization of spillovers over time.

As conjectured, IHPORTB shows that corporate innovations rely on more numerous and more "important" predecessors than universities (the differences though are significant for 1975 but not for 1980). This suggests that university research is located nearer the origins of innovational paths, and that this may be an aspect of basicness. ORIGINAL does not live up to expectations: there is a slight difference for 1980 but it lacks statistical significance, and for 1975 the difference even has the "urong" sign. SCIENCE does conform with the prior, and strongly so: university patents do rely relatively more on non-patent (i.e. scientific) sources than corporate patents (recall that this is cannot a "field effect", since the samples are matched by technology field). ${ }^{23}$

The results for the distance measures are veak and inconclusive: technological distance "works" for the 1980 sample but not for 1975, whereas distance in time does not work at all. In fact, in most cases the results for TIME (F and B) run contrary to the prior, that is, the follow-up innovations of corporations appear to take longer than those of universities. In sharp contrast to them, the appropriability measures do perform very vell: PSELF (F and B) is much larger for corporations than for universities, suggesting that corporations are in fact more successful at reaping the benefits of their own research.

In sum, with the exception of ORIGINAL, and with some reservation

${ }^{23}$ It is possible though that this result reflects to some extent differences in citation practices between university and corporate researchers, and not just genuine differences in the nature of their research (i.e. more "scientific"). However, the fact that there are symbiotic linkages between universities and corporations in fields such as biotechnology (where most of the NPCITES occur) would suggest that citation practices are actually similar; unfortunately our data cannot discriminate between these effects. 
regarding the time span of GENERAL, the contrast between universities and corporations does "validate" the measures of basicness and of appropriability, in the limited sense that we cannot reject with them the prior that universities do perform more basic research. On the other hand, the conceptual ambiguity of the distance measures surfaces also in the empirical results: there is some evidence to the effect that the offsprings from university innovations may be more remote in technology space, but certainly not in time. In general $\mathrm{F} /$ measures perform somewhat better than B/measures, and the 1980 sample shows crisper results than 1975 .

A subsidiary hypothesis was that the basicness measures would exhibit higher values for patents of top corporations (i.e. those belonging to the 200 corporations with the largest R\&D outlays) than for those of "other" corporations: presumably the larger corporations can afford to invest in more basic research, since they may be able to appropriate a larger fraction of the benefits. Table 4 shows that there may be something to it, but the differences are for the most part very slight; the one significant exception is appropriability, and to a lesser extent IMPORTF. Thus top corporations seem to generate more "important" innovations, and they do capture more of the benefits from them, but otherwise their research and research outcomes look similar to that of smaller RkD performers.

However, it is quite likely that the lack of contrast between them stems simply from the particular sample chosen, which is by no means representative of corporate research, but rather replicates exactly the technological composition of university (patentable) innovational efforts. Thus, it may well be the case that in those particular fields there is little difference between "small" and "big" firms, but that those differences do exist in the population of corporate innovations at large. In fact, a large proportion of our sample is in biotechnology, and we know that in this field small firms, both by themselves and in cooperation with universities, are particularly innovative.2

${ }^{24}$ In particular, that may explain the significantly lower value of IHPORTB for other-corp, which would imply that the smaller corporations engage in more "creative" research. 


\subsection{The links across the P/B divide: "technological trojectories"?}

Having shown that our measures capture indeed aspects of basicness, we use them now to address the next set of issues: does basic research lead to basic innovations? does the nature of the research efforts affect the features of the resulting innovations? As a first cut at these questions (and sidestepping causality), we look for preliminary evidence of statistical linkages between the characteristics of innovations and of research, by scrutinizing the correlations within and between F/ and B/measures. Looking once more at table 2, notice the similarity of the patterns of correlations of the $\mathrm{F} /$ measures to those of the $\mathrm{B} /$ measures: virtually every association of a pair of $F /$ measures is replicated by its equivalent B/pair (e.g. the correlation between GENERAL and TECHF mirrors that of ORIGINAL and TECHB, IMPORTF and GENERAL mirrors IHPORTB and ORIGINAL, etc.). What we find then is that equivalent $F / B$ measures tend to replicate each other, both in the shape of their distributions (recall the findings in section 5.1) and in relation to others, suggesting that the features of research and the features of the resulting innovations correspond to a common pattern.

Turning now to the correlations across the $F / B$ divide, notice in table 5 that the largest correlations are along the main diagonal, that is, between equivalent $F / B$ measures.25 Thus it would seem that "importance breeds importance", originality breeds generality, coming from far away in technology space leads far away as well, etc. In that sense, then, the (ex post) characteristics of patented innovations as they reveal themselves in the $F$ /measures appear to be related to the attributes of the research that lead to them. ${ }^{26}$ These systematic linkages between equivalent $F / B$ measures seem to suggest that technical change takes place along certain "technological trajectories", exhibiting coherence (in terms of the attributes of the

25The one exception is TIMEB which shows a higher correlation with IMPORTF (and sligthly higher with GENERAL) than with TIUEF; notice also that
SCIENCE does not have an equivalent $\mathrm{F} /$ measure.

${ }^{28}$ This echoes Kuznets' conjecture that "There is a positive correlation between the magnitude of the technical problem resolved by an invention and the magnitude of its technical potential". Kuznets (1962), p. 26. 
innovations that occur along them) and persistence (see Dosi 1982, 1988, and Freeman, 1990).

In order to pursue this theme further we constructed the following composite measures: IMPORTT $=($ IMPORTF + IMPORTB $) / 2$, GENERALT $=$ (GENERAL + ORIGINAL) $/ 2$, and TIMET $=($ TIMEF + TIMEB $) / 2$, and computed the correlations between them (averages for the two samples): Corr(IMPORTT, GENERALT) $=.29$, Corr (IMPORTT, TIMET) $=-.17$, Corr(GENERALT, TIMET) $=-.11$. Thus, certain paths of innovative activity are more likely to render important and general innovations over time, and these innovations would tend to follow each other in quick succession. 0ther paths are likely to result in run-of-the-mill and technologically focused innovations, and the advance along them is likely to be slow. In other words, there seem to be more and less "hot" innovational tracks, that persist at least over decade-long periods (the average time span in this study is of 14 years $\cong$ Mean(TECHB) + Mean(TECHF)).

\subsection{1 "production function" for basicness, and institutional effects}

Probing further into the links between basic research and basic innovations, ve run regressions of each of the F/variables on the B/measures, dumies for technological fields, and dummies for corporations. The purpose was twofold: first, to estimate a sort of production function whereby the attributes of the patented innovations play the role of "outputs" and the characteristics of the underlying research play the role of "inputs". Second, to see whether the differences in the means of the $F / m e a s u r e s$ between universities and corporations remain there after controlling for the characteristics of research and technological fields.

Table 6 shows the regressions of IMPORTF and GENERAL:27,28 in line with

27 Since we use the same set of regressors in all regressions, there was no point in estimating them jointly using Zellner's SUR.

$28 \mathrm{Ve}$ run similar regressions for TECHF and TIMEF as well, but virtually the only significant variable in each was the equivalent B/measure (TIMEB in the regression of TIMEF, and TECHB in TECHF), and hence there was no point in reporting them. 
the findings of table 5 , the most significant coefficient in the regression of IMPORTF is its equivalent B/measure, IMPORTB (and likewise ORIGINAL is the most significant in the regression of GENERAL). 29 Notice, hovever, that smaller values of IMPORTB mean that the patent is more "basic" in the sense of being closer to the roots of a given innovational path, and hence if basicness leads to basicness we would have expected a negative sign on the coefficient of IMPORTB. The positive and highly significant coefficient that we obtained may be seen instead as lending support to the notion of technological trajectories suggested earlier. Here that could be interpreted as follows: highly "creative" research (in the sense of small values of IMPORTB) is most likely to exhibit a large variance in terms of its outcomes - some may do extremely vell, others may fail miserably (i.e. high and low values of IHPORTF). On the other hand, once a research avenue has proven its worth (i.e. high values of IMPORTB), further significant innovations along those lines are very likely to come, showing up in high IMPORTF. If the latter effect dominates, we will find indeed a positive association between IMPORTF and IMPORTB .

The results in GENERAL are well in line with conventional wisdom: more original research, as well as research that draws from far removed technological areas (high TECHB), lead to innovations of wider technological significance. More reliance on scientific sources also enhances the generality of the outcomes (this finding does not hold for the 1975 sample). The negative signs on TIHEB in both regressions imply that more important and more general innovations stem from more recent (or up to date) research sources.

As to the second issue explored in these regressions, it is clear that there does remain an "institutional effect" after controlling for the type of research, meaning that even if universities and corporations were to engage in

${ }^{29}$ Since citation practices vary by technological fields, we suspected that these results might mean only that patents from citation-intensive fields get high values of IMPORTF and of IMPORTB. The results remain, hovever, even if dumies for 49 technological fields ("CATCODE") are included in the regressions. 
research having similar characteristics, universities vould still produce on average more "basic" innovations. Finally we note that the R''s of about .10 obtained in these regressions should not be judged harshly, considering that what we are trying to account for are attributes of innovations that have defied quantification up to now.

\subsection{Appropriability}

Economists have long regarded appropriability as one of the key notions in the economics of technical change, and yet its elusive nature has frustrated recurrent attempts to quantify it and thus to incorporate it in empirical studies of innovation (a notable exception is Levin et al 1987, and subsequent studies that used the Yale survey).

The measure of (actual) appropriability suggested here is PSELFF, defined as the fraction of citing patents granted to the same assignee as the one of the originating patent, and a similarly defined B/measure, PSELFB. Clearly, this is likely to be just a crude and partial measure: if for example the down-the-line benefits from an innovation do not involve further technical advances, or if they do but most of those subsequent innovations are not patented, then PSELF will be widely off mark. Thus, one of the key issues is whether or not the denominator of PSELF (i.e. the total number of citations) is indicative of total realized benefits: if that is the case then the fraction of self-citations may well be a good proxy for the ratio appropriated by the inventor, otherwise it surely will not.

We have already seen that PSELF ( $F$ and $B$ ) is significantly higher for top corporations than for other corporations, and higher for both vis a vis universities. The question now is what are the attributes of innovations that may influence actual appropriability, that is, what determines ex ante appropriability. Following the discussion in section 2.1 , we suggest as indicators of ex ante appropriability the measures of distance and generality, TIMEF (B), TECHF (B), and GENERAL (ORIGINAL). High values of TIMEF (B) mean that the follow-up innovations take long, and hence that the realization of the benefits occur far in the future; thus the innovation would be perceived 
ex ante as being "less appropriable", since it is less likely that the (private) inventor will be able to retain control over the innovational path long enough to enjoy the benefits. Similarly, suppose that the innovation results in marketable products in a wide range of fields, or in technologically distant fields. Presumably, it is more difficult to anticipate these spinoffs than those within the same field; or, as Nelson (1959) argued, if the firm is specialized it may not be able to take advantage of technological "diffused" or "remote" spillovers. Thus, the potential benefits associated with them would look ex ante less appropriable. As with time, distance and generality are likely to affect the incentives to innovate, and hence also the institutional distribution of research efforts.

A thorny problem is that these distance and generality measures are computed ex post, and hence they could be regarded as indicators of ex onte appropriability only if they are on average correctly anticipated by the inventors. Some evidence to that effect are provided by the findings related to technological trajectories: these suggest that the conditions of appropriability have some degree of persistence along these trajectories, and hence that inventors may be able to foresee to some extent the remoteness and generality of the expected fruits of their innovations. In addition, we shall use for this purpose a new variable, EAGENER ("ex ante generality"), defined as the number of distinct 3 -digit patent classes among the original and cross classifications to which the originating patent was assigned.30 As it turns out EAGENER is highly correlated with GENERAL, and also with TECHF. Since the classification is done at the time when the patent is assigned, EAGENER is certainly determined ex ante.

Table 7 shows regressions of PSELFF and PSELFB on these measures. The strongest result is the negative and very significant coefficient of TIME, $F$ and B. A straightforward reading of this finding is simply that spillovers

30 Patents are assigned to an "original" classification, and to any number of "cross" classifications: the former represents the main technological area which the innovation belongs to, the latter consist of additional areas which the patent examiner regards as related to the innovation. 
tend to occur in-house faster than externally. Thus the same R\&D organization can recognize earlier the potential for further developments of a given innovation, proceed along a pre-conceived research path that renders interrelated innovations, etc. For the converse reasons outsiders would take longer in benefiting from spillovers originating in labs other than their own. The leap of faith from this interpretation to appropriability is that inventors can somehow anticipate TIMEF (perhaps on the basis of TIMEB), and behave accordingly.

GENERAL and ORIGINAL fit the conjecture but just with borderline significance, and so does EAGENER. On the other hand TECHF and B do not at all (TECHF even exhibits a puzzling positive and significant coefficient for 1975). Thus it seems that appropriability has to do more with technological "focus" than with technological. "distance", at least as these are measured here. Notice also that the gap in the extent of actual appropriability between universities and corporations remains even after controlling for distance and generality, meaning that corporations are better at reaping the benefits from their innovations regardless of which technological trajectories they choose. Finally, we note that the results for 1980 are better than those for 1975 , which we take primarily as a reflection of data availability, both in the sense of number of observations and in the extent of missing data.

\section{Conclusions and Suggestions for Further Research}

This paper is first and foremost and attempt to quantify and clarify important aspects of the process of technical change (i.e. basicness and appropriability), and explore the linkages between them. He rely for that purpose on detailed patent data, thus awarding the proposed measures a very wide coverage, limited only by the extent to which innovations manifest themselves in patents: very basic scientific discoveries on the one hand, and minor improvements on the other would not be captured by our measures.

Relying on the prior that universities perform more basic research than corporations, we find that the forward-looking measures of importance and generality do seem to capture aspects of the basicness of innovations; 
similarly, the reliance on scientific versus technological sources, and (to a less extent) the closeness to the origins of innovational paths, appear to reflect aspects of the basicness of research. On the other hand the proposed measure of originality does not seem at all able to discriminate between more and less basic research.

The fraction of citations coming from patents awarded to the same inventor was found to be much higher for corporations than for universities, supporting the notion that PSELF may be indicative indeed of actual appropriability. The measures of technological distance appear to be related to basicness but the evidence is not clear-cut, whereas distance in time does not conform at all with the prior. In all, then, the initial validation of the measures rendered very satisfactory results for the $F /$ basicness and for the indicators of actual appropriability, less so for the measures of B/basicness, and all but failed for the distance measures.

A second set of findings revealed interesting similarities between equivalent $F$ and B measures, suggesting that there are strong "family effects" in successive generations of patents. Further work along these lines would seek to identify and characterize more in detail different technological trajectories, and relate them to conventional economic data. The analysis of appropriability shows that it tends to diminish with distance in time and to a lesser extent with the technological spread of research outcomes, but not with technological distance. As an extension, it would be interesting to relate these measures of appropriability to those obtained in the Yale Survey (Levin et al, 1987).

The results are thus quite encouraging, particulary if vieved as those of a pilot study. The next step would be to use these measures in tandem with other economic data coming from independent sources, and see whether or not they make a difference. The prime target would be to redo studies that have used simple patent counts as indicators of innovation, usually with disappointing results. In particular, we would like to re-examine the series of studies by Griliches and associates at the NBER (Griliches, 1981; Pakes, 
1985; Griliches and Cockburn, 1988), which sought to identify the impact of R\&D and of patent counts on the market value of Compustat firms. We hypothesize that if we were to use composite indicators based on our measures instead of simple patent counts, the impact on stock market value would be much more noticeable.

In particular, we expect that IMPORTF would have a very significant effect, and that it will improve even further when adjusting it with PSELFF, since what should influence the worth of the inventor is just the appropriable rents, not the total. Likewise, we expect that GENERAL would have a negative impact on the value of small firms, but not of highly diversified corporations. Another hypothesis is that the $\mathrm{B} /$ measures of basicness would be more closely related to R\&D expenditures than to indicators of performance such as market value. If these hypotheses are confirmed, that would pave the way for the wide-scale use of the proposed measures as key variables in empirical studies of innovation. 
Appendix: Further Comments of Tables 1 - 3

Note in table 1 that the large difference in the means of IMPORTF between the two samples ( 13 for 1975 versus 7 for 1980) is due simply to the fact that the 1975 patents had a 5-year longer forward time horizon; the same accounts for the differences in TIMEF. Even though the date of the originating patents should not matter for the availability of $B / m e a s u r e s$, in fact it does because of the higher fraction of missing data that we encounter the further back in time we go; that accounts for the difference in the means of TIMEB between the two cohorts, and may also explain in part the differences in IMPORTB.

Similarly to GENERAL and to ORIGINAL, there is also a large mass at zero for SCIENCE, which reflects a very large proportion of zeros for NPCITES. This is related to same extent to the distribution of patents by technological fields: for the 1980 sample about 50\% of the patents with non-zero NPCITES belong to Drugs and Medical, whereas this field accounts for just $37 \%$ of the sample. Clearly, it is more of a common practice to cite non-patent sources in Drugs and Medicine than in say, Hechanical Arts or Electronics.

Ve noted that IMPORTF and GENERAL exhibit a significant correlation, and likewise IMPORTB and ORIGINAL. One would probably expect a positive correlation between NCITING and GENERAL simply because the distribution of NCITING is very skewed, and few citations necessarily imply high concentration and hence low values of GENERAL (the same for NCITED and ORIGINAL). In fact, the correlations between these variables are on the order of 0.33 , which seems to suggest that the "spurious" aspect of it does not dominate.31 Horeover IMPORTF comprises also second-generation citations, and those do not enter into the computation of GENERAL. Thus there is some indication that more "important" patents tend to be also more "general", and likewise that innovations stemming from more "important" origins tend to be more "original".

Ve noted above the similarity in the distributions and correlations patterns of equivalent $F$ and $B$ measures. It is quite clear that these results are not spurious, since the F/variables "occur" independently of the backward ones, and are literally ex post whereas the backward measures are set ex ante. Thus for example when an patent is issued, the value of ORIGINAL for it is already determined; as time goes by the said patent may receive any number of citations, and these may be distributed in any way across patent classes, so that $T$ years later it will show a certain realized value of GENERAL. From the point of view of the construction of these measures there is clearly no need for them to exhibit similar distributions or patters of correlations with other variables. The fact that they do is then an empirical finding that reflects something real about the underlying process of technical change.

${ }^{31}$ The logic of the relationship between NCITING and GENERAL is the same as that between market size and the Herfindahl (one minus it): one would expect very small markets to be highly concentrated, but for the rest of the distribution it is not clear at all how the relationship goes (in fact it seems that very large markets are highly concentrated). 


\section{BIBLIOGRAPHY}

Arrow, K.J.: "Economic Velfare and the Allocation of Resources for Inventions," in R. Nelson (ed.) The Rate and Direction of Inventive Activity, Princeton University Press, 1962

Carpenter, M.P., Narin F. and Wolf P., "Citation Rates to Technologically Important Patents." Yorld Patent Information, Vol. 3. No.4., 1981.

Carpenter, M. and F. Narin.: "Validation Study: Patent Citations as Indicators of Science and Foreign Dependence," Vorld Patent Information, Vol.5, No. 3, pp. 180-185, 1983.

Cohen, W. M. and R. C. Levin, "Empirical Studies of Innovation and Market Structure". In R. Schmalansee and R. Willig (eds.), Handbook of Industrial Organization, North-Holland, 1989.

Cohen, W. H. and D. Levinthal: "Innovation and Learning: The Two Faces of R\&D." Economic Journal, 1989.

Cockburn, I. and Z. Griliches, "Industry Effects and Appropriability Measures in the Stock Market's Valuation of R\&D and Patents". American Economic Review, Papers and Proceedings, 1988 (78), pp. 419-423.

Dasgupta, P. and P. David.: "Information Disclosure and the Economics of Science and Technology," Chapter 16 in G. Feiwel (ed.), Arrow and the Ascent of Yodern Economic Theory, NYU Press, 1987.

Dorfman, N: "Route 128: The Development of a Regional High-Technology Economy" in D. Lampe (ed.), The Yassachusetts Yiracle: High Technology and Economic Revitalization. Cambridge: MIT Press, 1988.

Dosi, G. "Technological Paradigms and Technological Trajectories: A Suggested Interpretation of the Determinants and Directions of Technological Change", Research Policy, 1982, 11(9), pp. 147-62.

Dosi, G. "Sources, Procedures, and Microeconomic Effects of Innovation". Journal of Economic Literature, 1988, 26(9), pp.1120-1171.

Freeman, C. The Economics of Industrial Innovation, 2nd ed. Cambridge: MIT Press, 1982.

Freeman, C. "Schumpeter's Business Cycles Revisited", in Heertje and Perlman (eds.), Evolving Technology and Market Structure, Studies in Schumpeterian Economics, Ann Arbor: The University of Michigan Press, 1990.

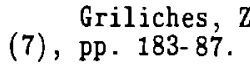

Griliches, Z. (ed.), R\&D, Patents and Productivity. University of Chicago Press, 1984 
Griliches, Z.: "Productivity, R\&D and Basic Research at the Firm Level in the 1970's." American Economic Reviev, 1986

Griliches, Z. "Patent Statistics as Economic Indicators: a Survey," Journal of Economic Literature, 1990, 27, pp. 1661-1707.

Jaffe, A.: "Technological Opportunity and Spillovers of R\&D: Evidence from Firms, Patents, Profits and Market Value," American Economic Review, 1986, 76(5), pp.984-1001.

Jaffe, A.: "Real Effects of Academic Research," American Economic Review, $1989,79(5)$, pp. $957-70$.

Jaffe, A., Trajtenberg, H. and Herderson, R. "Geographic Localization of Knovledge Spillovers, as Evidence by Patent Citations'. Quarterly Journal of Economics, 1992 (forthcoming).

Kuhn, Thomas, The Structure of Scientific Revolutions. Chicago: University of Chicago Press, 1962

Kuznets, S. "Inventive Activity: Problems of Definition and Measurement," in $R$. Nelson (ed.) The Bate and Direction of Inventive Activity, Princeton, NJ: Princeton University Press, 1962.

Levin, R., A. Klevorick, R.R. Nelson, and S.G. Vinter, "Appropriating the Returns from Industrial Research and Development," Brookings Papers on Economic Activity, 1987, 9, 783-820.

Mowery, D.C. and Rosenberg, N. Technology and the Pursuit of Economic Grorth, Cambridge: Cambridge University Press, 1989.

National Science Foundation, Science and Technology Data Book, Washington D.C. NSF 1985 .

National Science Foundation, Academic Science/Engineering RkD Funds, Fiscal Year 1987, 1989

Nelson, R. "The Simple Economics of Basic Scientific Research," Journal of Political Economy, 1959

Nelson, R. "The link between science and invention: the case of the transistor," in R. Nelson (ed.) The Rate and Direction of Inventive Activity, Princeton University Press, 1962

Pakes, Ariel, "On Patents, R\&D, and the Stock Harket Rate of Return". Journal of Political Econory, 1985, 93(2), pp. 390-409.

Pakes, Ariel, "Patents as 0ptions: Some Estimates of the Value of Holding European Patent Stocks", Econometrica, 1986, 54(4), pp. 755-84.

Rosenberg, N. Inside the Black Box: Technology and Economics. Cambridge, 
England: Cambridge University Press, 1982.

Trajtenberg, M. "A Penny for Your Quotes: Patent Citations and the Value of Innovations," Rand Journal of Economics, 1990a, 21(1), pp 172-187.

Trajtenberg, M. Economic Analysis of Product Innovation: The Case of CT Scanners. Cambridge, MA: Harvard University Press, $1990 \mathrm{~b}$.

Van Raan (ed), Handbook of quantitative Studies of Science and Technology, Amsterdam: North Holland, 1988.

Veingart, P. R. Sehringer and H. Vinterhager. "Bibliometric Indicators for Assessing Strengths and Veaknesses of Vest German Science," Chapter 13 in Van Raan (ed), Handbook of Quantitative Studies of Science and Technology, Amsterdam: North Holland, 1988.

Veizman, M. "On Diversity", Harvard Oniversity, Department of Economics, Vorking Paper Series, 1991. 
Table 1

Descriptive Statistics

(i) Basicness Veasures:

\begin{tabular}{|c|c|c|c|c|c|c|c|}
\hline Variable & & $\mathbf{N}$ & Yean & Std Dev & Sum & Minimum & Yaximum \\
\hline IMPORTF & $\left(\begin{array}{l}1975 \\
1980\end{array}\right)$ & $\begin{array}{r}948 \\
1446\end{array}$ & $\begin{array}{r}12.5786 \\
6.9575\end{array}$ & $\begin{array}{l}23.2100 \\
14.6781\end{array}$ & $\begin{array}{l}11925 \\
10061\end{array}$ & $\begin{array}{l}0 \\
0\end{array}$ & $\begin{array}{l}380.5000 \\
250.5000\end{array}$ \\
\hline GENERAL & & $\begin{array}{r}806 \\
1127\end{array}$ & $\begin{array}{l}0.3235 \\
0.2693\end{array}$ & $\begin{array}{l}0.2872 \\
0.2742\end{array}$ & $\begin{array}{l}260.7115 \\
303.4474\end{array}$ & $\begin{array}{l}0 \\
0\end{array}$ & $\begin{array}{l}0.8750 \\
0.8512\end{array}$ \\
\hline IMPORTB & & $\begin{array}{r}763 \\
1340\end{array}$ & $\begin{array}{l}21.3388 \\
27.7608\end{array}$ & $\begin{array}{l}22.1050 \\
33.3325\end{array}$ & $\begin{array}{l}16282 \\
37200\end{array}$ & $\begin{array}{l}0 \\
0\end{array}$ & $\begin{array}{l}204.5000 \\
393.5000\end{array}$ \\
\hline ORIGINAL & & $\begin{array}{r}719 \\
1261\end{array}$ & $\begin{array}{l}0.2247 \\
0.2717\end{array}$ & $\begin{array}{l}0.2691 \\
0.2736\end{array}$ & $\begin{array}{l}161.5900 \\
342.5935\end{array}$ & $\begin{array}{l}0 \\
0\end{array}$ & $\begin{array}{l}0.8200 \\
0.8819\end{array}$ \\
\hline SCIENCE & & $\begin{array}{r}945 \\
1446\end{array}$ & $\begin{array}{l}0.1355 \\
0.2023\end{array}$ & $\begin{array}{l}0.2519 \\
0.2962\end{array}$ & $\begin{array}{l}128.0122 \\
292.4922\end{array}$ & $\begin{array}{l}0 \\
0\end{array}$ & $\begin{array}{l}1.0000 \\
1.0000\end{array}$ \\
\hline
\end{tabular}

(ii) Distance Veasures:

$\begin{array}{lrrrrrr}\text { TECHF } & 791 & 0.3183 & 0.2983 & 251.7629 & 0 & 1.0000 \\ & 1124 & 0.3164 & 0.3143 & 355.6418 & 0 & 1.0000 \\ \text { TIMEF } & 811 & 7.2633 & 2.4875 & 5891 & 0 & 13.0000 \\ & 1126 & 4.3754 & 1.5501 & 4927 & 0 & 9.0000 \\ & & & & & & \\ \text { TECHB } & 708 & 0.3141 & 0.3378 & 222.4072 & 0 & 1.0000 \\ & 1261 & 0.3003 & 0.3081 & 378.6438 & 0 & 1.0000 \\ \text { TIMEB } & 909 & 7.6583 & 3.9544 & 6961 & 0 & 17.0000 \\ & 1367 & 9.1720 & 4.8534 & 12538 & 0 & 22.0000\end{array}$

(iii) Ippropriability leasures:

$\begin{array}{lrrrrrr}\text { PSELFF } & 783 & 0.1069 & 0.2399 & 83.6737 & 0 & 1.0000 \\ & 1061 & 0.1556 & 0.2920 & 165.1267 & 0 & 1.0000 \\ \text { PSELFB } & 719 & 0.1411 & 0.2981 & 101.4825 & 0 & 1.0000 \\ & 1342 & 0.1259 & 0.2473 & 168.9854 & 0 & 1.0000\end{array}$

The top line of each variable corresponds to the 1975 sample, the bottom one to the 1980 sample. 
Table 2

Correlations ${ }^{a}$ Between Measures of the same Type - 1980 Sample

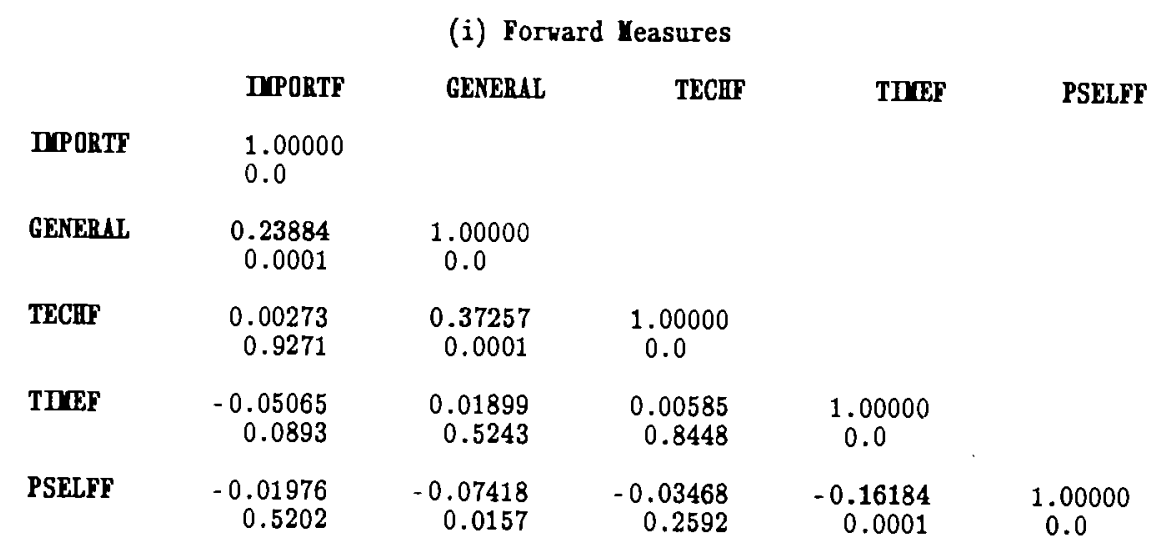

(ii) Backwards Measures

\begin{tabular}{|c|c|c|c|c|c|c|}
\hline & DPORTB & ORIGINAL & TECHB & TIEB & PSELFB & SCIENCE \\
\hline IUPORTB & $\begin{array}{c}1.00000 \\
0.0\end{array}$ & & & & & \\
\hline ORIGINAL & $\begin{array}{r}0.30641 \\
0.0001\end{array}$ & $\begin{array}{c}1.00000 \\
0.0\end{array}$ & & & & \\
\hline TECHB & $\begin{array}{r}0.01442 \\
0.6090\end{array}$ & $\begin{array}{r}0.43794 \\
0.0001\end{array}$ & $\begin{array}{c}1.00000 \\
0.0\end{array}$ & & & \\
\hline TINEB & $\begin{array}{r}-0.12605 \\
0.0001\end{array}$ & $\begin{array}{r}-0.10846 \\
0.0001\end{array}$ & $\begin{array}{r}0.04796 \\
0.0887\end{array}$ & $\begin{array}{c}1.00000 \\
0.0\end{array}$ & & \\
\hline PSELFB & $\begin{array}{r}-0.03578 \\
0.2042\end{array}$ & $\begin{array}{r}-0.08317 \\
0.0031\end{array}$ & $\begin{array}{r}-0.06184 \\
0.0282\end{array}$ & $\begin{array}{r}-0.20613 \\
0.0001\end{array}$ & $\begin{array}{l}1.00000 \\
0.0\end{array}$ & \\
\hline SCIRKCE & $\begin{array}{r}-0.16230 \\
0.0001\end{array}$ & $\begin{array}{r}-0.06578 \\
0.0195\end{array}$ & $\begin{array}{r}-0.00508 \\
0.8571\end{array}$ & $\begin{array}{r}-0.17287 \\
0.0001\end{array}$ & $\begin{array}{r}-0.02025 \\
0.4587\end{array}$ & $\begin{array}{c}1.00000 \\
0.0\end{array}$ \\
\hline
\end{tabular}

apearson correlation coefficients; significance probabilities right under. 
Table 3

Comparison of Means: Universities vs. Corporations

(i) Basicness Veasures

$$
\text { Universities Corporations }
$$

$\begin{array}{lll}\text { IMPORTF }(1980) & 8.80 & 6.04 * * * \\ & 16.76 & 10.49 * * * \\ \text { GENERAL } & 0.31 & 0.25^{* * *} \\ & 0.34 & 0.31^{\mathrm{a}} \\ & & \\ \text { IHPORTB } & 26.83 & 28.22 \\ & 16.31 & 23.75 * * \\ \text { ORIGINAL } & 0.28 & 0.27 \\ & 0.20 & 0.24 \\ \text { SCIENCE } & 0.28 & 0.16^{* * *} \\ & 0.20 & 0.10^{* * *}\end{array}$

(ii) Distance Veasures

TECHF

$\begin{array}{ll}0.35 & 0.30^{* * *} \\ 0.32 & 0.31 \\ 0.33 & 0.29 * * \\ 0.30 & 0.92\end{array}$

TIMEF

4.44

4.34

TECHB

6.48

$7.69 \mathrm{~b}$

TIMEB

9.08

9.22

7.50

7.79

(iii) Ippropriability Ieasures

$\begin{array}{lll}\text { PSELFF } & 0.09 & 0.19 * * * \\ & 0.07 & 0.13^{* * *} \\ \text { PSELFB } & & \\ & 0.06 & 0.16^{* * *} \\ & 0.14 & 0.14\end{array}$

The top row of each variable corresponds to 1980 , the bottom to 1975. In italics: figures for which the differences from universities have the "wrong" sign (i.e. contrary to the prior).

*,**,***: differences from the mean of university patents statistically signicant at the $.1, .05$ and .01 level respectively.

"The difference is significant for a "truncated" sample - see text.

bStatistically significant but in the "vrong" direction. 
Table 4

Comparison of Yeans: Top versus 0ther Corporations

(i) Basicness leasures

IMPORTF $\left(\begin{array}{l}1980) \\ 1975\end{array}\right)$

GENERAL

IMPORTB

ORIGINAL

SCIENCE

(ii) Distance Ieasures

TECHF

TECHB

TIMEF

TIMEB
Top- Corp.

$$
6.67
$$

11.83

0.25

0.32

32.16

23.00

0.26

0.24

0.17
0.11

0.17
0.11

0.30

0.32

0.28

0.31

4.27

7.52

8.98

7.52
Other-Corp.

5.41*

$9.16^{*}$

0.24

0.30

$24.14^{\circ}$

24.44

0.27

0.23

0.16

0.10

0.10

0.29

0.31

0.29

0.99

4.41
7.85

9.45

7.99

(iii) Ippropriability Measures

PSELFF

PSELFB
0.24
0.16
$0.13 * * *$
0.10 ***
0.19
0.19
$0.13 * * *$

The top row of each variable corresponds to 1980, the botton to 1975 . In italics: figures for which the differences from top-corp. have the "wrong"

*,**,***: differences from the mean of top-corp. patents statistically signicant at the $.1, .05$ and .01 level respectively.

bdifference statistically significant but in the "wrong" direction. 
Table 5

Correlations ${ }^{a}$ Across F/B Measures

1975

\section{IMPORTF}

IPPORTB

$$
\begin{array}{r}
0.24651 \\
0.0001
\end{array}
$$

ORIGINAL

0.08039

0.0311

TECHB

TIIEB

PSELFB

SCIFNCE

$$
\begin{array}{r}
0.05906 \\
0.1164
\end{array}
$$

$$
-0.12464
$$

0.0002

$-0.02115$

0.5713

$-0.05102$

0.1170
TECIIF

$$
-0.06931
$$

0.0788

0.15370

0.0001

0.32970

0.0001

-0.01841
0.6128

-0.11319
0.0016

0.04388

0.2738

$-0.03886$

0.2711
0.03994
0.3243

$-0.00674$

0.8501
TIIEF

$\begin{array}{rr}0.02421 & -0.01046 \\ 0.5349 & 0.7918\end{array}$

0.07853

0.06144

0.0499

0.1312

\subsection{1}

0.7894

0.08186

0.11177

0.0018
$-0.02514$
0.5308

$-0.07365$

0.0368

1980

$\begin{array}{lrrrrr} & \text { TIPORTF } & \text { GENERAL } & \text { TECHF } & \text { TIEF } & \text { PSELFF } \\ \text { IUPORTB } & 0.25564 & 0.11549 & -0.04681 & 0.04647 & 0.01460 \\ & 0.0001 & 0.0002 & 0.1297 & 0.1322 & 0.6458 \\ \text { ORIGLNAL } & 0.05487 & 0.24628 & 0.20265 & -0.01127 & 0.00605 \\ & 0.0514 & 0.0001 & 0.0001 & 0.7213 & 0.8521 \\ \text { TECHB } & -0.02012 & 0.18751 & 0.38723 & -0.02765 & 0.05124 \\ & 0.4756 & 0.0001 & 0.0001 & 0.3817 & 0.1143 \\ \text { TIIEB } & -0.16763 & -0.11465 & 0.00468 & 0.09005 & -0.01243 \\ & 0.0001 & 0.0002 & 0.8781 & 0.0031 & 0.6917 \\ \text { PSELFB } & 0.05691 & -0.05004 & -0.01364 & -0.04648 & 0.21125 \\ & 0.0371 & 0.1030 & 0.6573 & 0.1299 & 0.0001 \\ \text { SCIENCE } & -0.00537 & 0.05175 & 0.03790 & -0.02885 & 0.01749 \\ & 0.8382 & 0.0825 & 0.2042 & 0.3335 & 0.5692\end{array}$

aPearson correlation coefficients; significance probabilities right under. 
Table 6

Regressions of IMPORTF and GENERAL on B/Variables

\begin{tabular}{|c|c|c|c|c|}
\hline & \multicolumn{2}{|c|}{ IXPORTF } & \multicolumn{2}{|c|}{ GENERAL } \\
\hline & 1975 & 1980 & 1975 & 1980 \\
\hline Constant & $\begin{array}{l}19.7 \\
(5.7)\end{array}$ & $\begin{array}{c}8.2 \\
(5.1)\end{array}$ & $\begin{array}{c}0.3 \\
(6.8)\end{array}$ & $\begin{array}{c}0.2 \\
(5.9)\end{array}$ \\
\hline IHPORTB & $\begin{array}{c}0.3 \\
(6.7)\end{array}$ & $\begin{array}{c}0.1 \\
(8.8)\end{array}$ & $\begin{array}{l}0.0005 \\
(0.9)\end{array}$ & $\begin{array}{l}0.0005 \\
(1.9)\end{array}$ \\
\hline ORIGINAL & $\begin{array}{l}-4.0 \\
(-1.0)\end{array}$ & $\begin{array}{c}-2.2 \\
(-1.2)\end{array}$ & $\begin{array}{r}0.11 \\
(2.3)\end{array}$ & $\begin{array}{c}0.18 \\
(4.8)\end{array}$ \\
\hline TECHB & $\begin{array}{c}7.0 \\
(2.3)\end{array}$ & $\begin{array}{l}-0.04 \\
(-0.02)\end{array}$ & $\begin{array}{c}0.17 \\
(4.7)\end{array}$ & $\begin{array}{r}0.11 \\
(3.4)\end{array}$ \\
\hline TIMEB & $\begin{array}{c}-0.3 \\
(-0.8)\end{array}$ & $\begin{array}{c}-0.4 \\
(-3.9)\end{array}$ & $\begin{array}{l}-0.005 \\
(-1.4)\end{array}$ & $\begin{array}{r}-0.005 \\
(-2.2)\end{array}$ \\
\hline SCIENCE & $\begin{array}{c}-6.1 \\
(-1.0)\end{array}$ & $\begin{array}{c}1.6 \\
(0.8)\end{array}$ & $\begin{array}{l}-0.04 \\
(-0.5)\end{array}$ & $\begin{array}{c}0.14 \\
(3.7)\end{array}$ \\
\hline $\mathrm{TC}$ & $\begin{array}{l}-8.7 \\
(-3.8)\end{array}$ & $\begin{array}{c}-3.1 \\
(-3.0)\end{array}$ & $\begin{array}{l}-0.03 \\
(-1.3)\end{array}$ & $\begin{array}{l}-0.05 \\
(-2.4)\end{array}$ \\
\hline $\mathrm{OC}$ & $\begin{array}{c}-13.0 \\
(-5.6)\end{array}$ & $\begin{array}{c}-3.0 \\
(-2.9)\end{array}$ & $\begin{array}{r}-0.05 \\
(-1.8)\end{array}$ & $\begin{array}{l}-0.05 \\
(-2.3)\end{array}$ \\
\hline $\mathrm{R}^{2}$ & 0.12 & 0.10 & 0.09 & 0.11 \\
\hline \# obs. & 707 & 1259 & 612 & 1002 \\
\hline
\end{tabular}

t-values in parentheses

All regressions include 4 dummies for technological "fields" 
Table 7

Regressions of Appropriability Measures

(i) PSELFF

1975

1980

\begin{tabular}{lcccc}
\hline Intercept & 0.19 & 0.19 & 0.24 & 0.24 \\
GENERAL & $(6.3)$ & $(6.0)$ & $(7.5)$ & $(7.5)$ \\
EAGENER & -0.06 & & -0.04 & \\
& $(-1.9)$ & -0.012 & $(-1.2)$ & -0.012 \\
TECHF & & $(-1.5)$ & & $(-1.5)$ \\
& 0.11 & 0.092 & -0.00 & -0.001 \\
TIMEF & $(3.2)$ & $(3.0)$ & $(-0.1)$ & $(-1.0)$ \\
CORP & -0.02 & -0.02 & -0.03 & -0.03 \\
& $(-5.3)$ & $(-5.2)$ & $(-5.1)$ & $(-5.3)$ \\
R2 & 0.08 & 0.07 & 0.09 & 0.09 \\
\# of obs. & $(4.2)$ & $(4.0)$ & $(4.9)$ & $(5.0)$ \\
\hline
\end{tabular}

(ii) PSELFB

\begin{tabular}{lcc} 
& 1975 & 1980 \\
\hline Intercept & 0.21 & 0.19 \\
ORIGINAL & $(6.3)$ & $(9.2)$ \\
TECHB & -0.08 & -0.09 \\
& $(-1.6)$ & $(-3.3)$ \\
TIMEF (B) & 0.04 & 0.00 \\
CORP & $(1.0)$ & $(0.1)$ \\
& -0.01 & -0.01 \\
R2 & $(-2.6)$ & $(-7.2)$ \\
\# of obs. & -0.00 & 0.10 \\
\hline
\end{tabular}

$t$ values in parenthesis. 


\section{United States Patent}

[54] TOMOGRAPIIIC SCANNER WITII CADMIUM TUNGSTATE SCINTILLATION CRYSTALS

[75] Inveniors: Rolnnd WY. Carlson, Lyndliurst; Carl T. Jngntich, Clingrin Falk, both of Olito

[73] Assignee: Ohio Nuclear, Inc., Solon, Ohio

(21) Appl. No.: 927,602

[22] Filed: Jul. 24, 1978

[51] Int, Cl.2 G01T 1/20

[\$2] U.S. CI. 250/361 R; 250/368 $250 / 445 \mathrm{~T}$

[58] Field of Scarch $250 / 361 \mathrm{R}, 363 \mathrm{R}, 363 \mathrm{~S}$ $250 / 366,367,369,445 \mathrm{~T}, 483$ References Cited

\section{U.S. PATENT DOCUMENTS}

\begin{tabular}{|c|c|c|}
\hline 39.839 & $8 / 1977$ & Carlier et al. ...... \\
\hline & $1 / 1978$ & 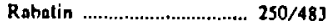 \\
\hline & $1 / 1978$ & I. ..................250/445 $T$ \\
\hline 4,116 & $9 / 1978$ & $250 / 445 \mathrm{~T}$ \\
\hline & $3 / 1979$ & $\ldots \ldots \ldots \ldots, 250 / 445 \mathrm{~T}$ \\
\hline
\end{tabular}

\section{OTHER PUBLICATIONS}

Sciulillation Counlers, Dirks, Mc(jraw-Hill, 1953, pp. 56-6I, 121-125.

Luminescence and the Scinlillalion Counier, Curran, Butlerworths Scienlific Publications, London, PP. 82-89, 131-135.

Photoeffects in Silicon Surface-Larrier Diodes, Jour- nal of Applied Pliysics, Luzzolino et al., vol. 33. No. 1, Jan. 1962, pp. 148-155.

Dismuth Germanate: A ligh-Z Gamma Ray and Charged Particle Detector, Harshaw Chemical Co., Solon, Ohio, pp. 1-6.

Harshaw Scintillation Phosphors, Harslıaw Chemical Co., Solon, Oliio, 1975.

Harshaw Chemical Catalog, Other Harshaw Scintillalion Phosphors, pp. 20-21, (date unknown).

Primary Examiner-Davis $\mathbf{L}$. Willis Allorney, Agent, or Firm-Fay \& Sharpe

ABSTRACT

A radialion delector suitable for use in tomographic scanners comprising at least one cadmium tungstate scintillation crystal optically coupled will a silicon photodiode or other photoelectric transducers. A plurality of cadmium tungstate crystals may be coupled to one silicon pliotodiode with fiber optic light guides. In a tomographic scanner, radiation passing through the scan circle impinges on the cadmium tungstale crystals causing them to scintillate. The light scintillated strikes the ares of the p-n junction of the photodiode causing the photoelectric effect to be manifested. The intensity of radiation striking the cryatal is determined by measuring the photoconductive conductance, photoemissive current or photovoltaic potential. From these in. tensitiex all image is computed of the radiation attenua. tion in the examined scan circle.

21 Clelms, 4 Draning Figures

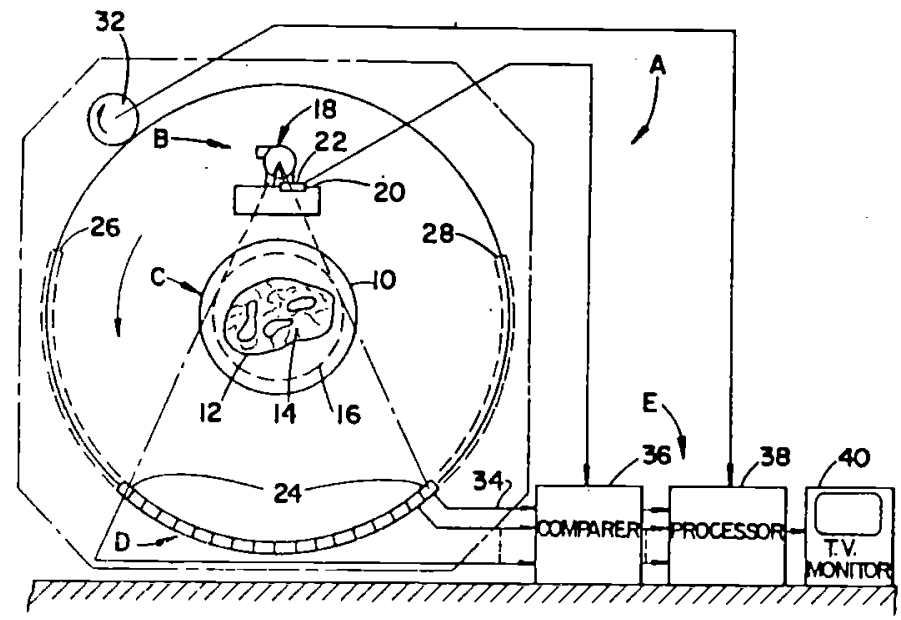


FIGURE 2

Distribution of Research Outcomes according to "Basicness"

a. The prior regarding the location of Universities ( $\left.F_{U}\right)$ vs. Corporations ( $F_{C}$ )

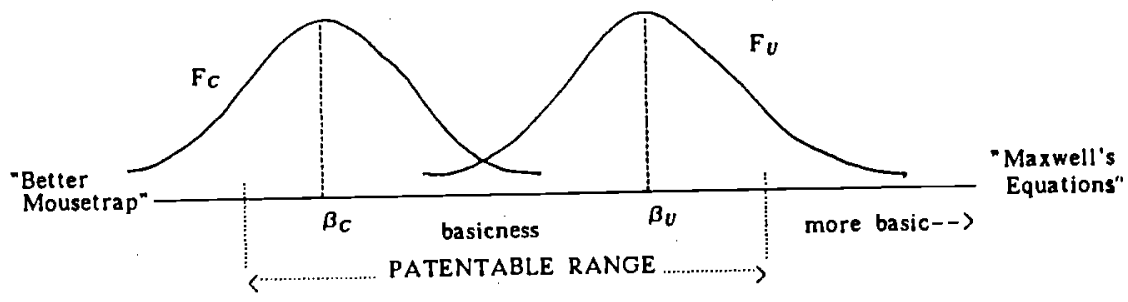

b. Ifypothetical selectivity bias leading to high prob, of type II error

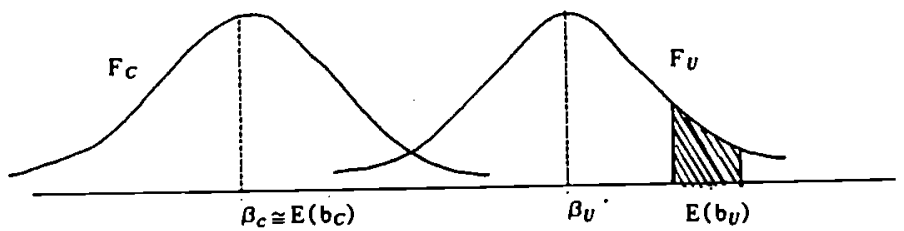

c. Selectivity bias which does not affect the validity of the Indicators (low prob. of type II error)

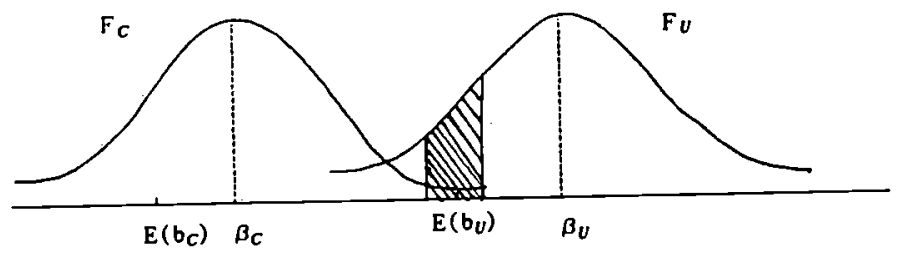


Figure 3: Sample Design

1975 Cohort

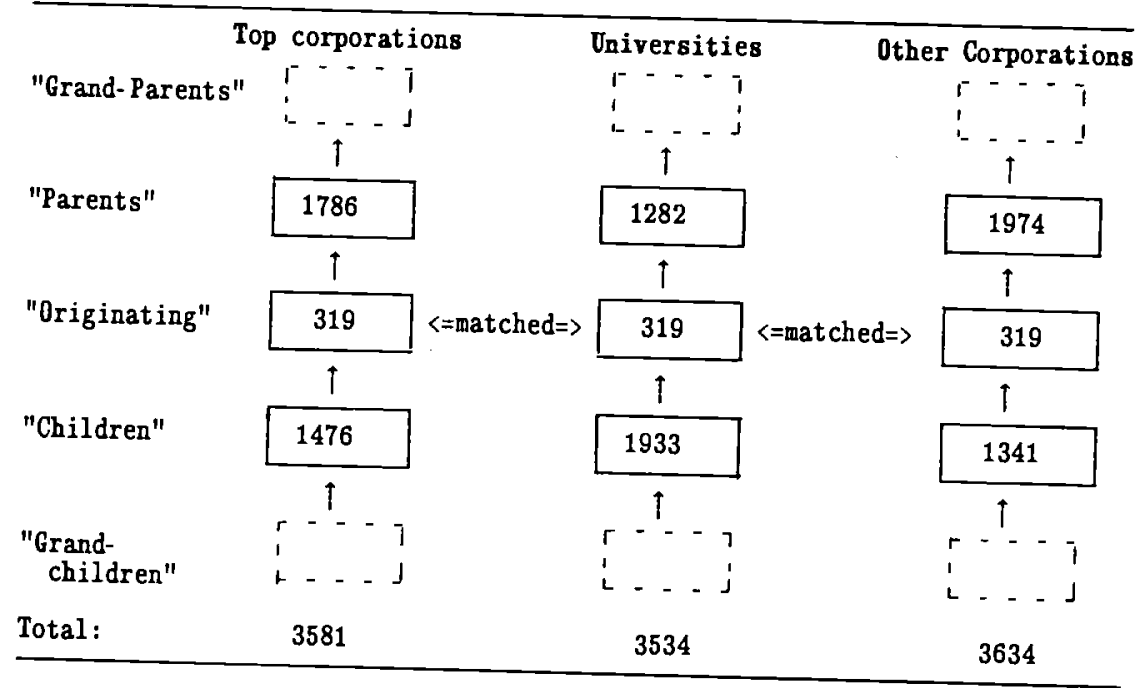

1980 Cohort

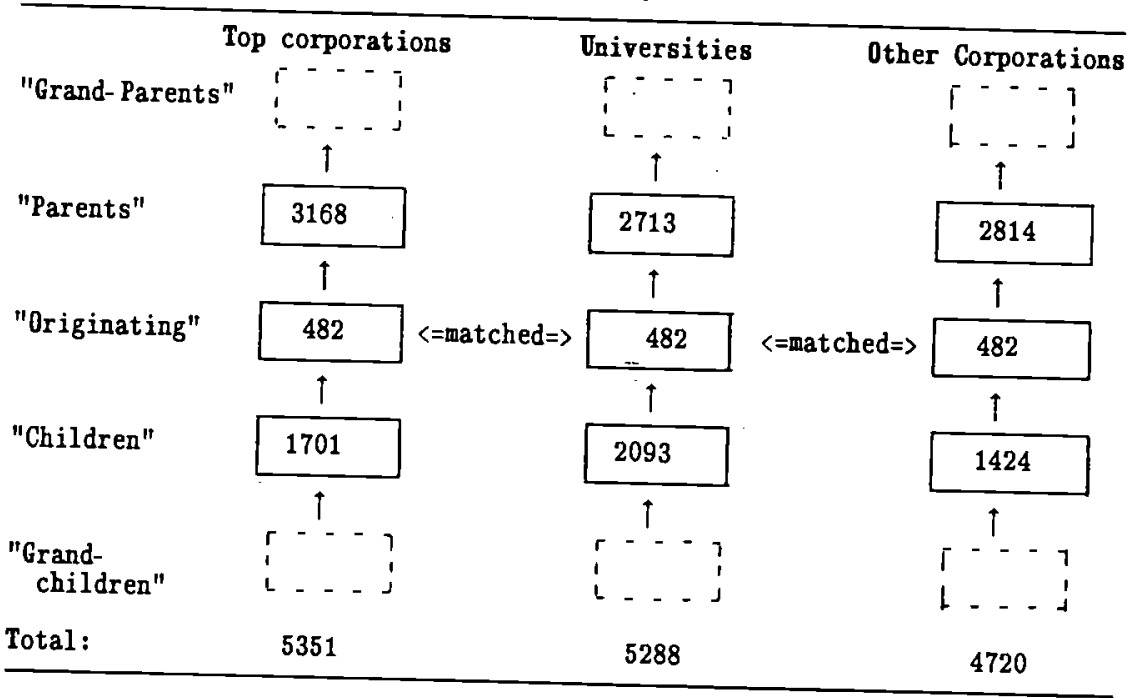

Total \# of patents for 1975: 10,749; for 1980: 15,359; Grand total: 26,108 


\section{FIGURE 4}

Computing the Measures of Basicness: An Illustration

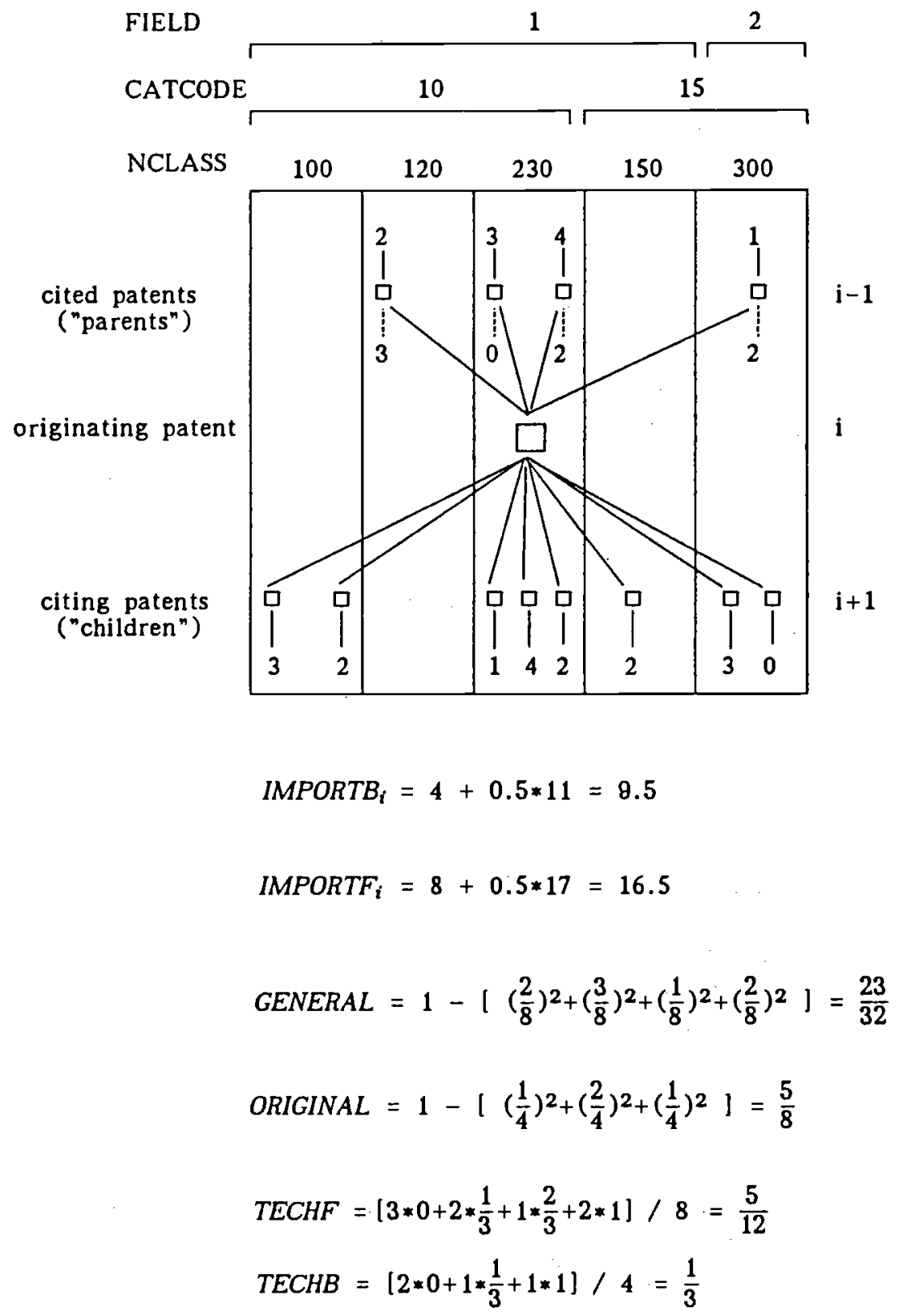


FIGURE 5

Frequency Distribution of Basicness Measures

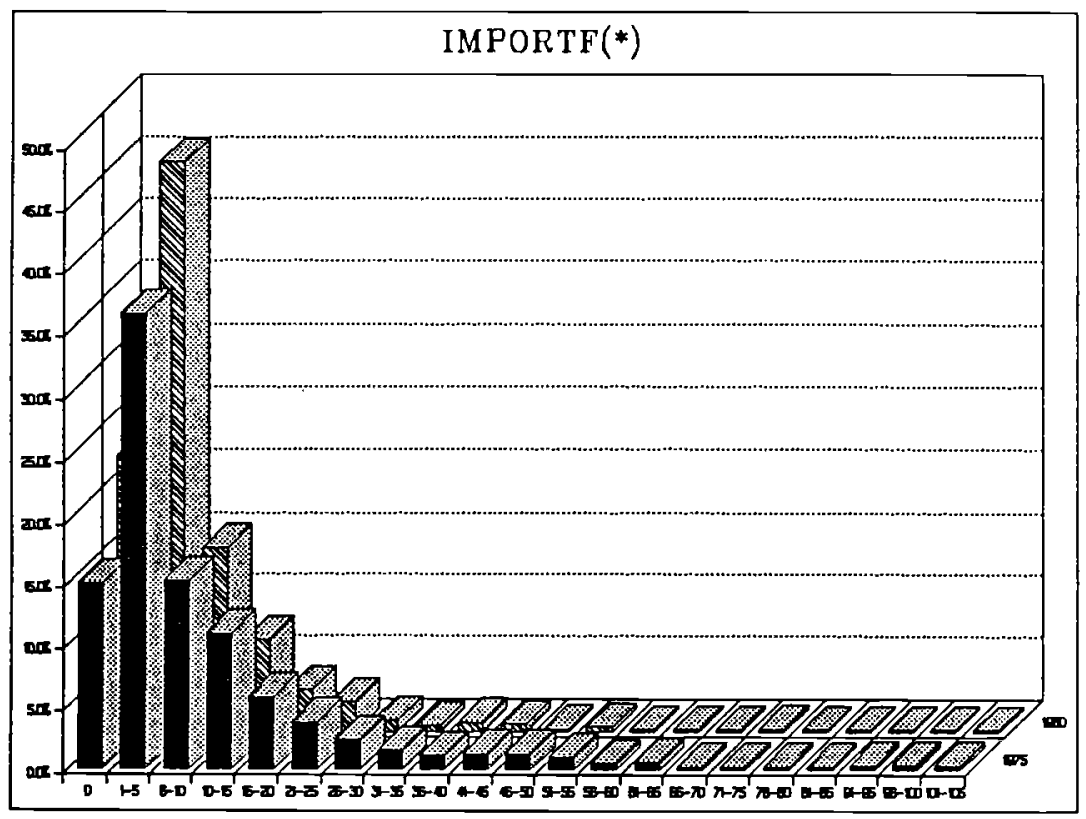

(*)Truncated-Values of IMPORTF>105 do not a ppear

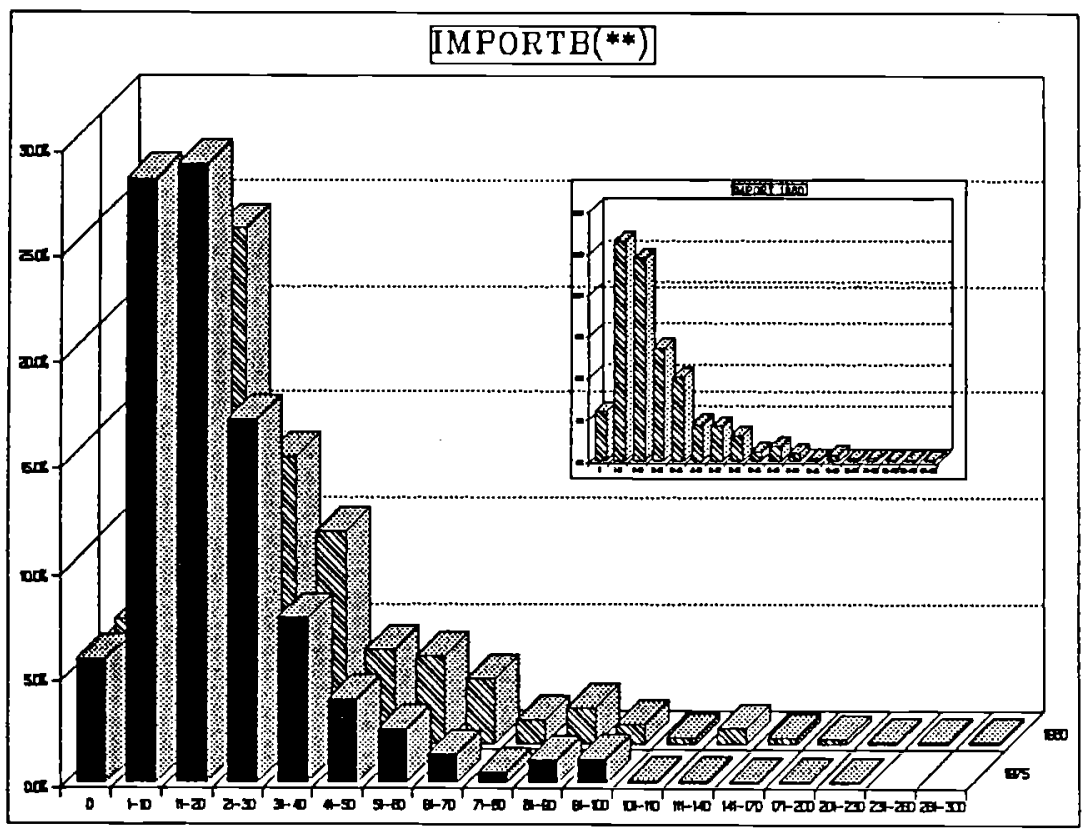

(*) Truncated-Values of IMPORTB $>300$ do not appear 
FIGURE 6

Frequency Distribution of Basicness Measures
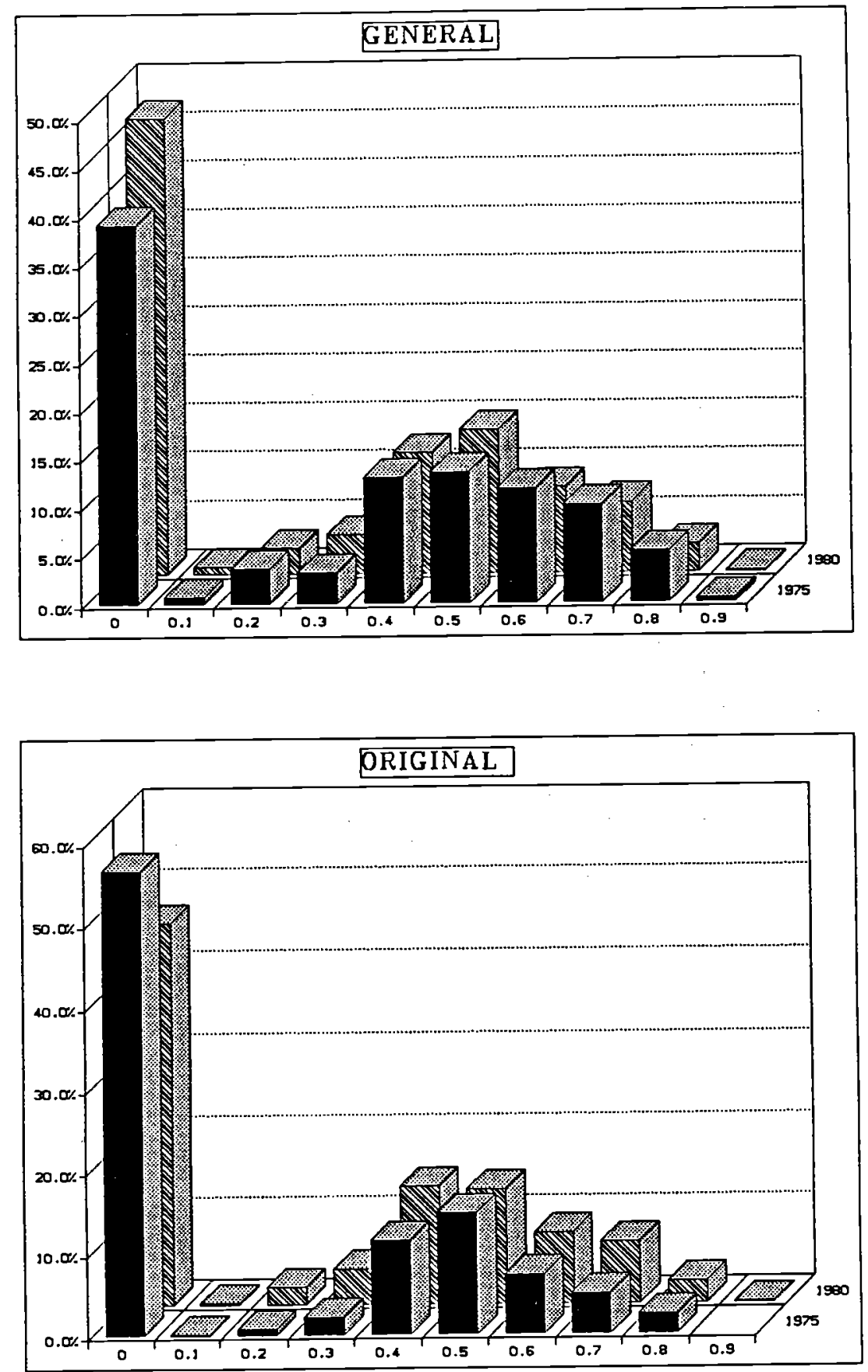